\title{
INVESTIGATION AND ANALYSIS OF A PILE FOUNDATION DAMAGED BY LIQUEFACTION DURING THE 1995 HYOGOKEN-NAMBU EARTHQUAKE
}

\author{
SHUNJI FuJiI ${ }^{\mathrm{i})}$, NorIAKI ISEMOTO ${ }^{\mathrm{ii})}$, YASUHIKo SATOU ${ }^{\mathrm{iii})}$, \\ OSAMU KANEKo ${ }^{\mathrm{ii})}$, HideKI FUnAHARA ${ }^{\mathrm{i})}$, TOSHIAKI ARA ${ }^{\mathrm{iii}}$ \\ and KoHJI TOKIMATSUiv)
}

\begin{abstract}
During the 1995 Hyogoken-Nambu earthquake, extensive liquefaction occurred on reclaimed lands causing serious damage to pile foundations. This paper reports the investigation of the damage to a pile foundation located in a liquefied soil as well as the results of its static and dynamic response analyses. Three piles of the building were examined by inserting a remote controlled television camera and an inclinometer into the hollow spaces of the piles. Serious damage was observed at the bottom of the fill where the piles were bent toward southwest. No serious damage was observed near the pile heads except for a shear crack found on one pile. Dynamic effective stress response analyses were conducted on a soil column and a soil-pile-building system and the process of the damage to piles was analyzed. The effect of the non-liquefied crust overlying liquefied soils on pile stresses due to inertial force is analyzed in detail, and the soil stiffness to be used in analyses is proposed. Pseudo-static analyses were conducted using a model consisting of a beam on nonlinear Winkler type springs. The effects of input parameters and the applicability of the pseudo-static analysis are examined by comparing the numerical results with the observed damage and with the results of the dynamic analyses.
\end{abstract}

Key words: earthquake damage, effective stress, finite element method, liquefaction, pile, subgrade reaction (IGC: E8)

\section{INTRODUCTION}

During the 1995 Hyogoken-Nambu earthquake, extensive liquefaction occurred on reclaimed lands. A three story steel building built on piles suffered serious differential settlement, suggesting the existence of serious damage to piles. An investigation of the piles was periformed by excavation around the pile head and by inserting a remote controlled television camera and an inclinometer into the hollow spaces of the piles. Serious damage to the piles was observed at the bottom of the fill. Dynamic analyses on the ground and the soil-pilebuilding model, as well as pseudo-static analyses were conducted to clarify the cause and the process of the damage.

\section{INVESTIGATION OF DAMAGE}

\section{Soil, Building, and Outline of Damage}

Figure 1 shows the location of the building, which is lo- cated on a man-made island filled with a gravelly sand during the period of 1964-1970. It is a 3 story office building made of structural steel completed in 1973. The nearest quay wall is about $350 \mathrm{~m}$ to the north.

Figure 2 shows the soil profile, SPT- $N$ value, shear wave velocity, and modulus of deformation $E_{0}$, obtained by the soil investigation conducted after the earthquake. The surface layer is the reclaimed fill of well graded decomposed granite soils, called Masado, with SPT- $N$ values of 2-15. It can be expected to liquefy during earthquakes. The subsequent layers are the original seabed layer of alluvial clay, and the layered composite of diluvial sand and clay layers. The ground water table was estimated to be at a depth of approximately $2.5 \mathrm{~m}$.

Figure 3 shows a plan of the foundation. A prestressed concrete pile is located under each column. It is a PC pile type-A according to the specifications of Japanese Industrial Standard, which has a concrete strength of $49.0 \mathrm{MPa}$ and a prestress of $3.92 \mathrm{MPa}$. These piles have diameters of $0.35 \mathrm{~m}$ for the corner piles and

i) Technolgy Research Center, Taisei Corp., 344-1, Nase-cho, Totsuka-ku, Yokohama 245-0051.

ii) Technology Research Center, Toda Corp.

iii) Technology Research Center, Nishimatsu Corp.

iv) Professor, Tokyo Institute of Technology, 2-12-10-Okayama, Meguro-ku, Tokyo 152-8552.

Manuscript was received for review on September 6, 1997.

Written discussions on this paper should be submitted before April 1, 1999 to the Japanese Geotechnical Society, Sugayama Bldg., 4F, Kanda Awaji-cho, 2-23, Chiyoda-ku, Tokyo 101-0063, Japan. Upon request the closing date may be extended one month. 


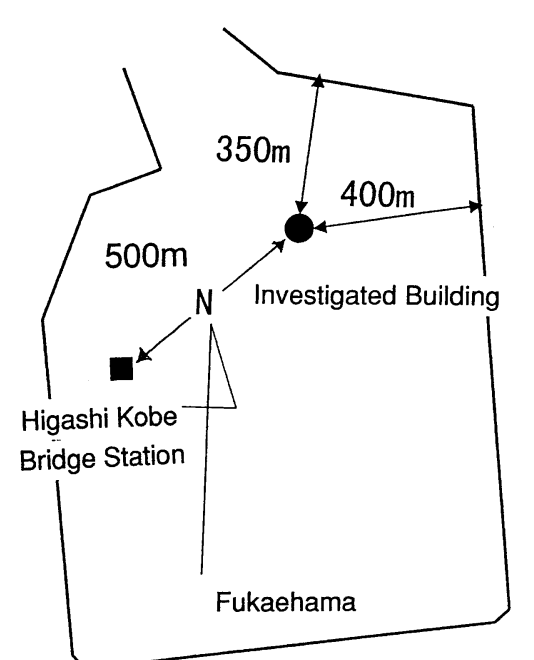

Fig. 1. Location of the investigated building

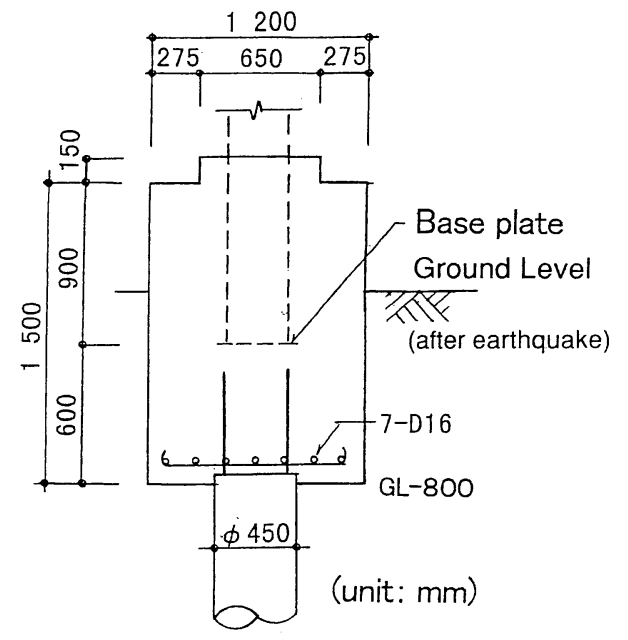

Fig. 4. Details of pile to pile cap joint

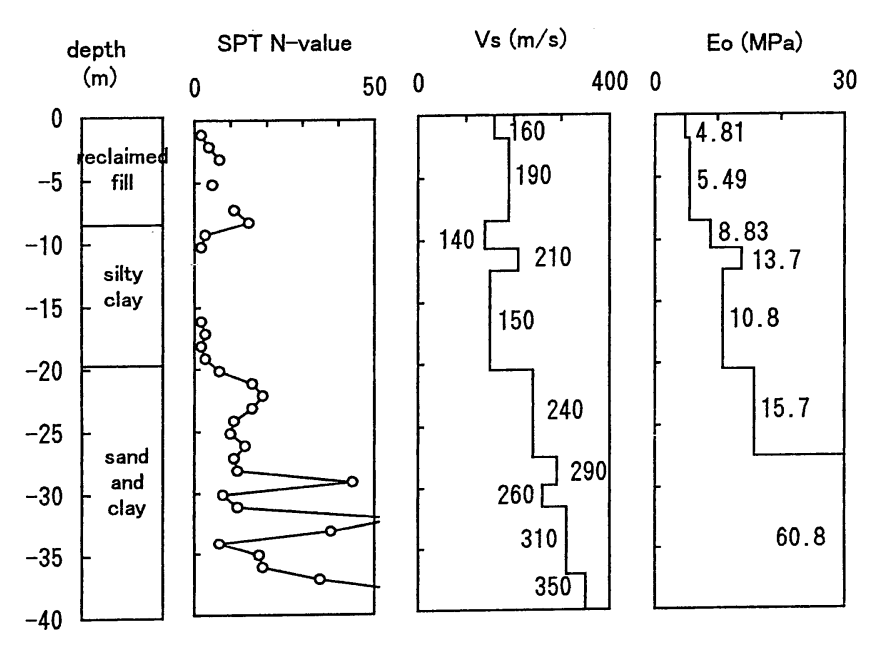

Fig. 2. Soil profile

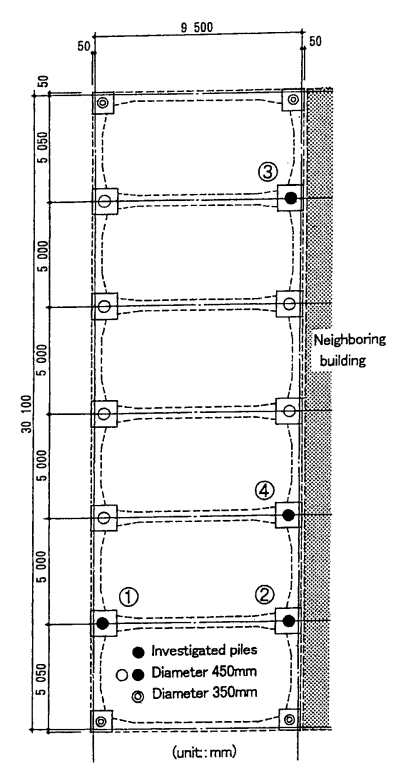

Fig. 3. Plan of foundation
$0.45 \mathrm{~m}$ for others, and the length is $28 \mathrm{~m}$, composed of two piles joined at a depth of $13 \mathrm{~m}$ below the ground surface. The piles were driven into the diluvial sand layer by a diesel hammer. The design dead loads are $640 \mathrm{kN}$ for the corner piles and $930 \mathrm{kN}$ for others. Figure 4 shows the details of the pile to pile cap joint. The pile cap is 1.2 $\mathrm{m}$ square and is $1.5 \mathrm{~m}$ high for piles of $0.45 \mathrm{~m}$ in diameter. The dimension is $1.0 \mathrm{~m}$ square for piles of $0.35 \mathrm{~m}$ in diameter. Footing girders are $0.45 \mathrm{~m}$ wide (extended to $0.65 \mathrm{~m}$ at both ends) and $0.9 \mathrm{~m}$ high. The pile head is embedded into the pile cap to approximately $6 \mathrm{~cm}$, and 9 prestressing tendons of $9 \mathrm{~mm}$ diameter, are anchored into the pile cap to a length of about $55 \mathrm{~cm}$. The location of the pile head was about $80 \mathrm{~cm}$ below the ground surface after the earthquake.

After the earthquake, sand boils and settlements of $30-60 \mathrm{~cm}$ were observed at the site, indicating that liquefaction occurred during the earthquake. The building tilted in a southwest direction and exhibited a vertical gap of the floor level to the neighboring warehouse. The building suffered functional problems such as blocked doors, breakage of pipings, some floor cracks on a floor, and minor cracks on non-structural walls, while no clear damage to structural members was observed. After demolishing the building the inclination of the foundation was measured. The foundation was inclined towards southwest, resulting in settlements of 21 to $25 \mathrm{~cm}$ (tilt angle of $1 / 38-1 / 45$ ) in the east-west direction and 35 to 39 $\mathrm{cm}$ (tilt angle of $1 / 77-1 / 86$ ) in the north-south direction.

Measurements of the permanent displacement of the building and the surrounding ground were conducted by comparing the aerial photographs before and after the earthquake. The identified displacement of the building at the roof level was $55-65 \mathrm{~cm}$, including the displacement by tilting, in the southwest direction as described in Fig. 5, which is consistent with similar measurements done by Hamada et al. (1995).

\section{Investigation of Damage to Piles}

Four piles indicated in Fig. 3 were selected and observa- 


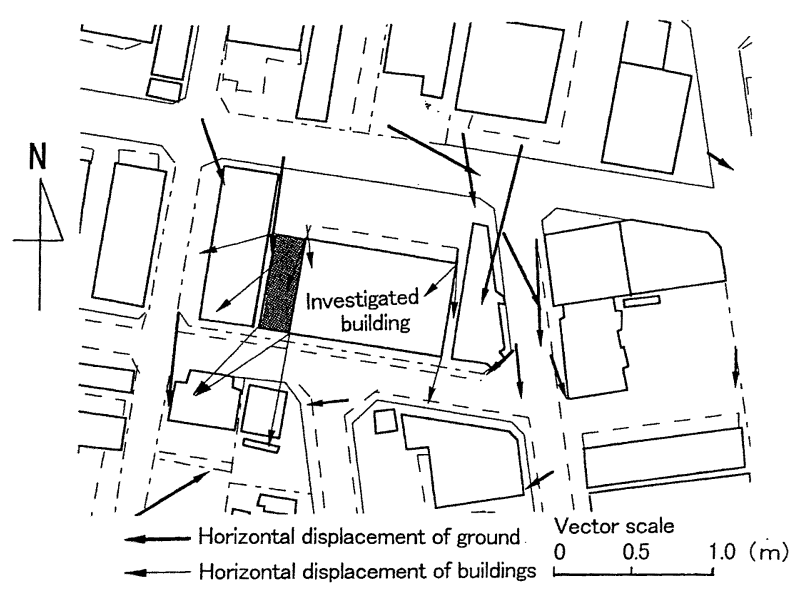

Fig. 5. Horizontal displacement of surrounding ground and buildings

tion of the pile head part was carried out after excavation of the surrounding soil. Sonic integrity tests were also conducted. A shear crack which separated $1 / 3$ of the pile section was observed on Pile No. 2, while no damage was observed on other piles. In the sonic integrity test, clear reflection from a depth of $9 \mathrm{~m}$ below the ground surface was recorded on each pile, indicating the existence of cracks at that level. Reflection from $6 \mathrm{~m}$ below the ground surface was also recorded on Piles No. 2 and No. 3 , while no clear reflection from the pile tips was recorded on each pile.

For Piles No. 1, No. 2, and No. 3, observation of damage by television camera and measurement of residual displacement by inclinometer were conducted. The inclinometer which was modified from the one used by Ohnishi et al. (1997) is depicted in Photo. 1. Figure 6 shows the measured residual displacement along the depth, and Fig. 7 shows the residual deformation modes projected on a horizontal plane, which are relative to the pile tips for Piles No. 2 and No. 3 and to the $7.5 \mathrm{~m}$ below the ground surface for Pile No. 1. As an inclination of about $1 / 100$ presumably due to a construction error was measured at a depth below $9 \mathrm{~m}$ on Pile No. 2, the measured residual displacement for Pile No. 2 is corrected by deducting the assumed initial inclination of $1 / 100$. In Pile No. 1, the hollow space in the pile was filled with some objects, which might be crushed concrete, at a depth of about $8 \mathrm{~m}$, so the deeper measurements could not be made. The measured residual displacement of Pile No. 2 and No. 3 indicates that these piles were bent at a depth of about $9 \mathrm{~m}$ towards southwest, proving the validity of the sonic integrity tests. The inclination above a depth of $9 \mathrm{~m}$ was $1 / 28-1 / 47$ in the north-south direction and $1 / 21-1 / 57$ in the east-west direction, which is consistent with the measured inclination near the pile head.

Figure 8 shows extended elevations of the inside walls of piles which are drawn based on the recorded view by the television camera. Some parts were not clearly observed due to muddy water. Many cracks are observed at depths between 3-6 $\mathrm{m}$ from the ground surface, and large cracks which accompany concrete fracture along

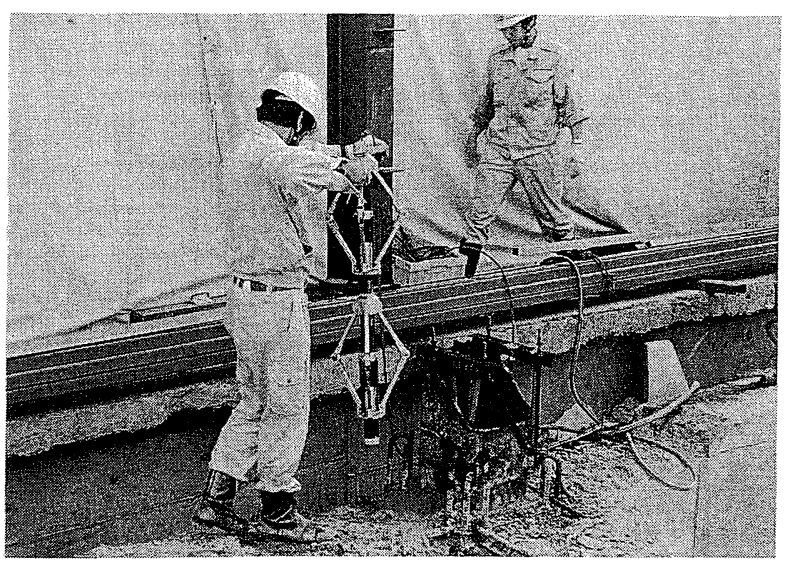

Photo. 1. Inclinometer

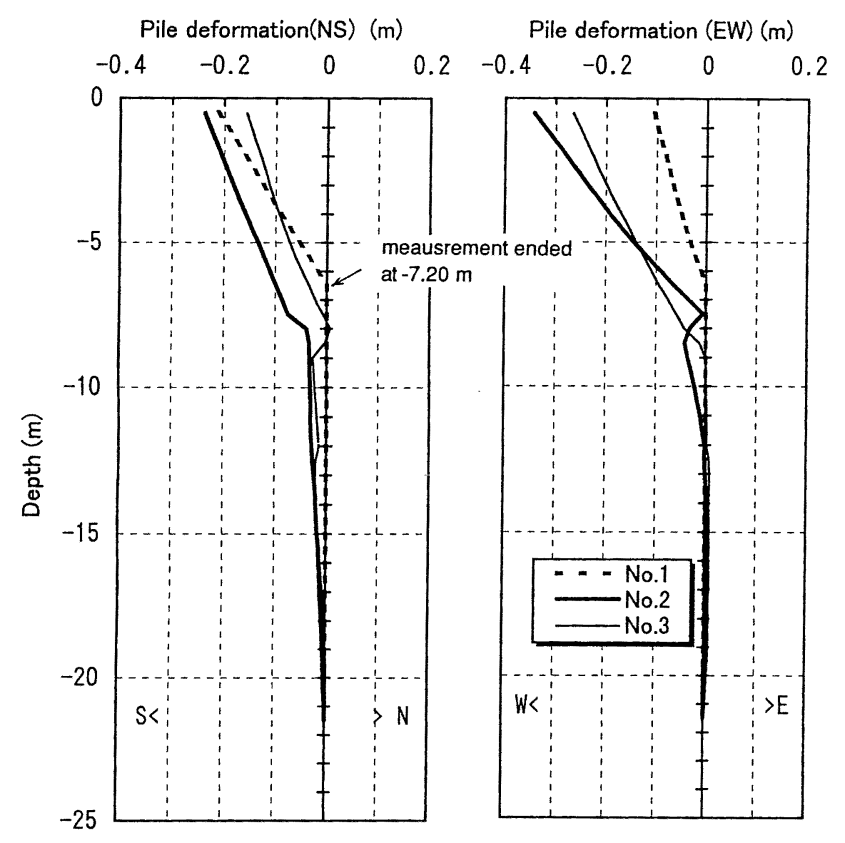

Fig. 6. Residual pile deformation modes (along the depth)

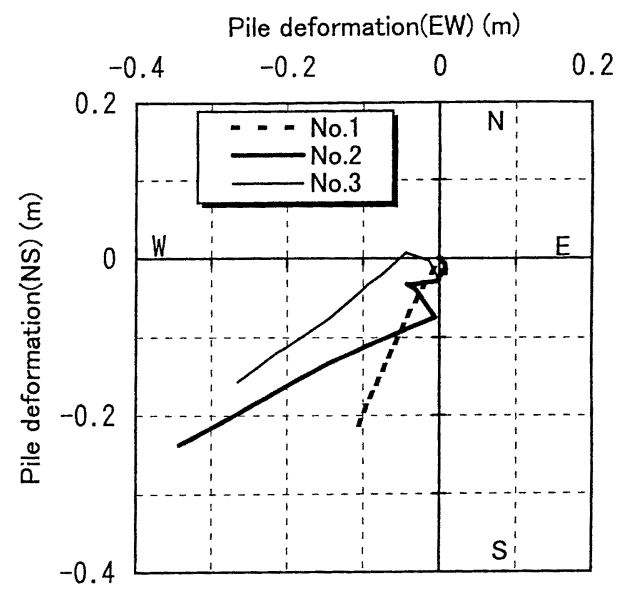

Fig. 7. Residual pile deformation modes (horizontal plane) 


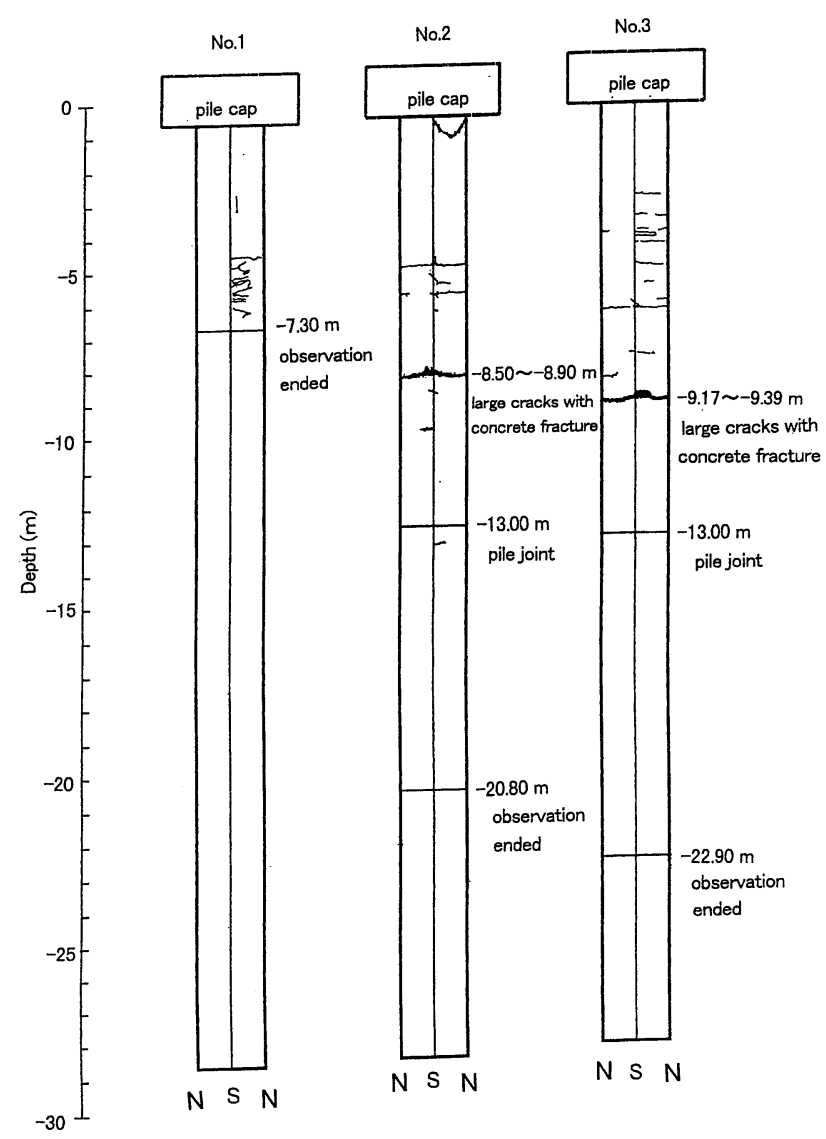

Fig. 8. Failure modes of piles obtained by television observation

the whole pile section are observed on Piles No. 2 and No. 3. The inside elevation of Pile No. 3 is shown in Photo. 2. The failure of these piles occurred at a depth about $1 \mathrm{~m}$ below the border between the reclaimed fill and the underlying alluvial clay layer. The observed depth of failure validates the measurements of the sonic integrity test and the inclinometer survey. It is assumed that these Vailures were caused by the amplified deformation of the ground due to soil liquefaction in the reclaimed fill. Below the depth of failure, including the joints at a depth of

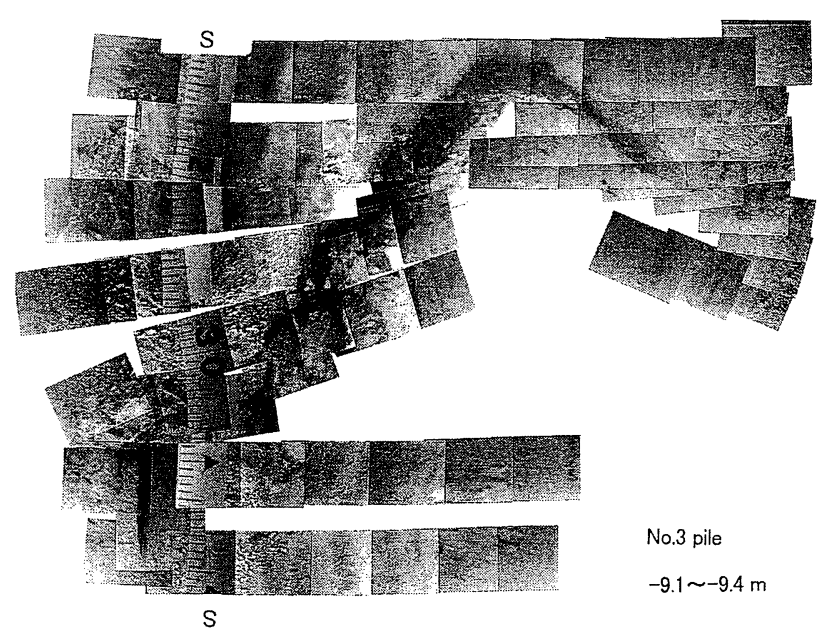

Photo. 2. Extended elevation of pile inside walls about $13 \mathrm{~m}$, no damage was observed.

\section{MODELING OF SOIL AND DYNAMIC RESPONSE ANALYSIS}

\section{Modeling of Soil}

Undisturbed samples of the reclaimed fill of the gravelly sand were recovered by a triple tube sampler, at a depth of $6 \mathrm{~m}$ below the ground levels where the SPT $N$ value is about 5 to 6 . The grain size distribution curve of the sample tested is shown in Fig. 9. The gravelly sand has a mean grain size $D_{50}$ of 0.6 to $1.8 \mathrm{~mm}$ and a fines content of 4 to $7 \%$, showing similarity to other samples and sand boils recovered at the Kobe Port Island (Miwa et al., 1997). The results of the undrained cyclic triaxial tests are shown in Fig. 10 in terms of the cyclic stress ratio and the number of cycles causing $5 \%$ axial strain in double amplitude. The liquefaction resistance of the recovered sample is similar to those for other samples of Masado soil by frozen sampling and by triple tube sampling (Miwa et al., 1997).

The behavior of the recovered reclaimed fill was modeled by the 'Stress-density model' (S-D model) (Cubrinovski, 1993). The dilatancy parameters of the model were determined to fit the liquefaction resistance obtained in the laboratory test. The simulated values are plotted in Fig. 10. The computed shear stress-strain relations and the effective stress paths for the cyclic stress ratio of 0.3 are presented in Fig. 11.

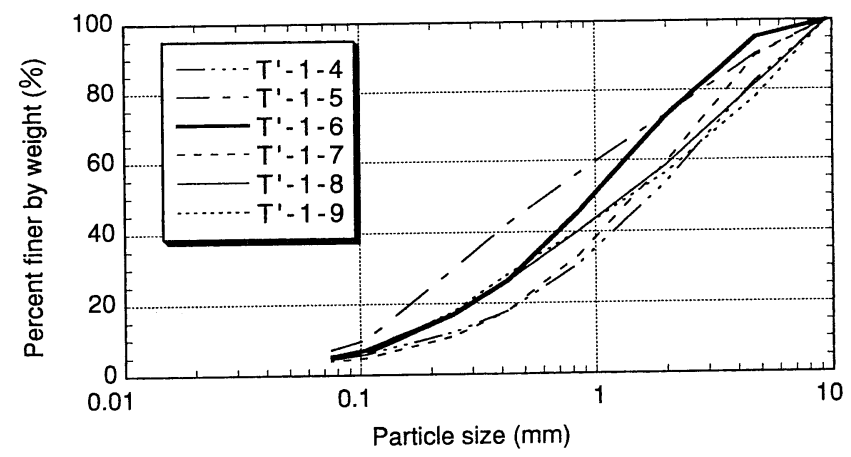

Fig. 9. Grain size distribution of reclaimed fill

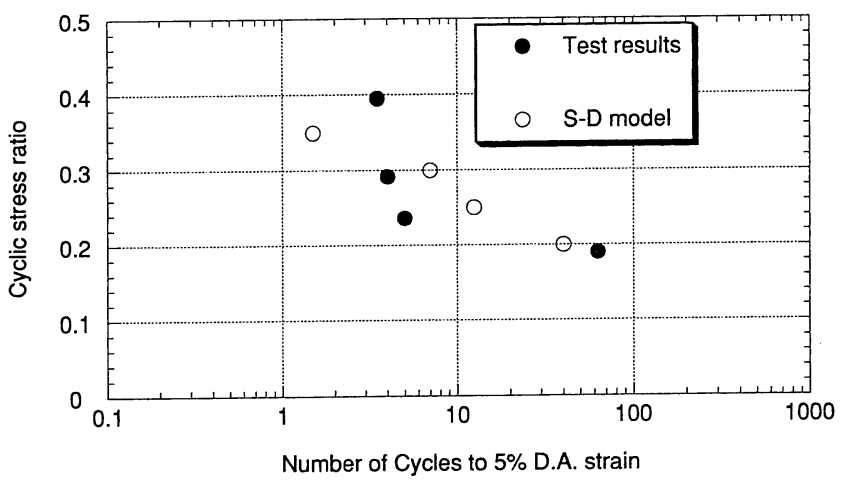

Fig. 10. Cyclic stress ratio versus number of cycles 

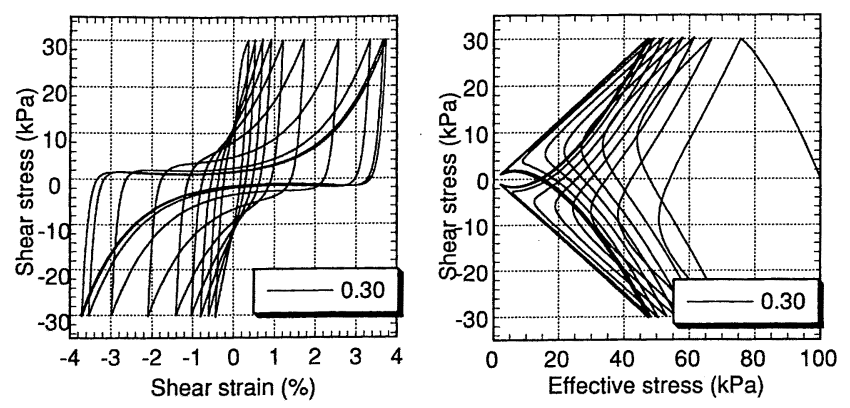

Fig. 11. Behavior of constitutive model

\section{Dynamic Response Analysis of Ground}

A fully coupled effective stress analysis of the ground was conducted using a finite element code DIANA-J with the S-D Model as a constitutive model. The 1-D soil column model representing the ground from the ground surface to a depth of $27.5 \mathrm{~m}$, is shown in Fig. 12. The reclaimed fill under the water table (depths of $2.5 \mathrm{~m}-8.5$ $\mathrm{m}$ ) was modeled with the S-D Model, while both the fill above the water table and the alluvial clay were modeled with a total stress nonlinear model having hyperbolic hysteresis curve. The tabulated values of $G_{0}$ and the $\tau_{\max }$ in Fig. 12 are those used to construct constitutive models. The strong motion record in the N-S direction observed at the Higashi Kobe Bridge Station, which is about $500 \mathrm{~m}$ from the building, was used as an input to the soil column model. The acceleration time history of the input motion is shown in Fig. 13.

Computed time histories of ground surface acceleration, displacement, and excess pore pressure ratios at three depths in the reclaimed fill, are shown in Fig. 14, and the distribution of the maximum acceleration and the maximum ground displacement are plotted in Fig. 15. The labels A, B, C, and D in Fig. 14, are times at which the pseudo-static analyses were conducted; these will be presented in the subsequent section. The pore pressure ra-

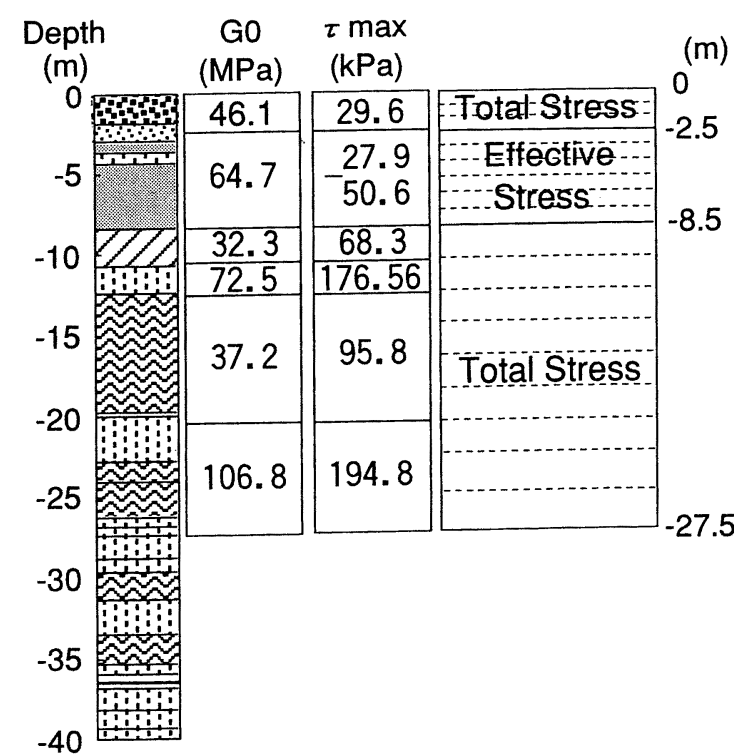

Fig. 12. Numerical model (soil column)

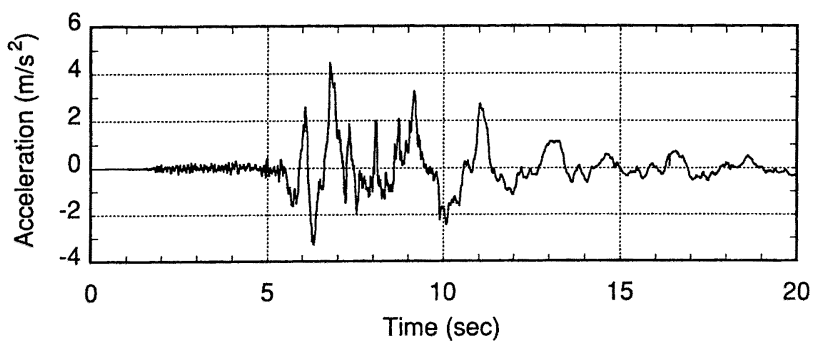

Fig. 13. Input motion (GL-33 m, E348N)
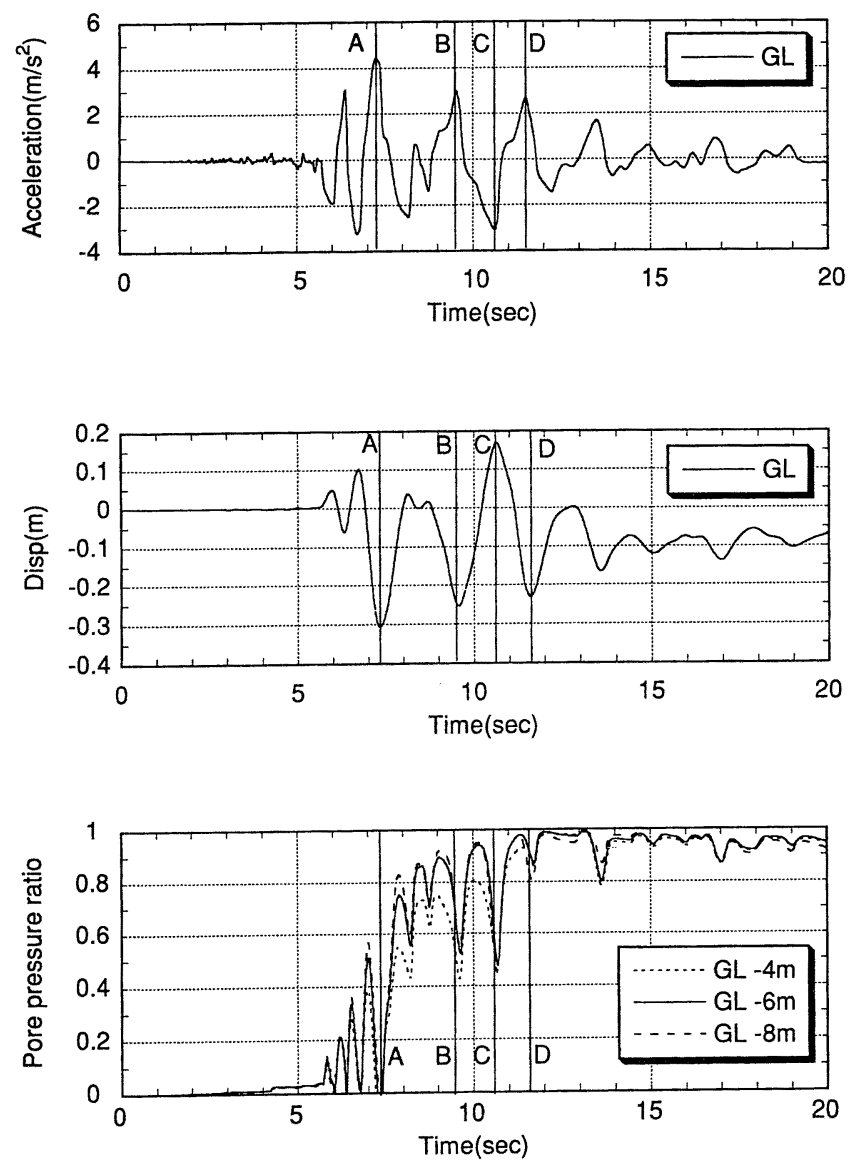

Fig. 14. Response of ground
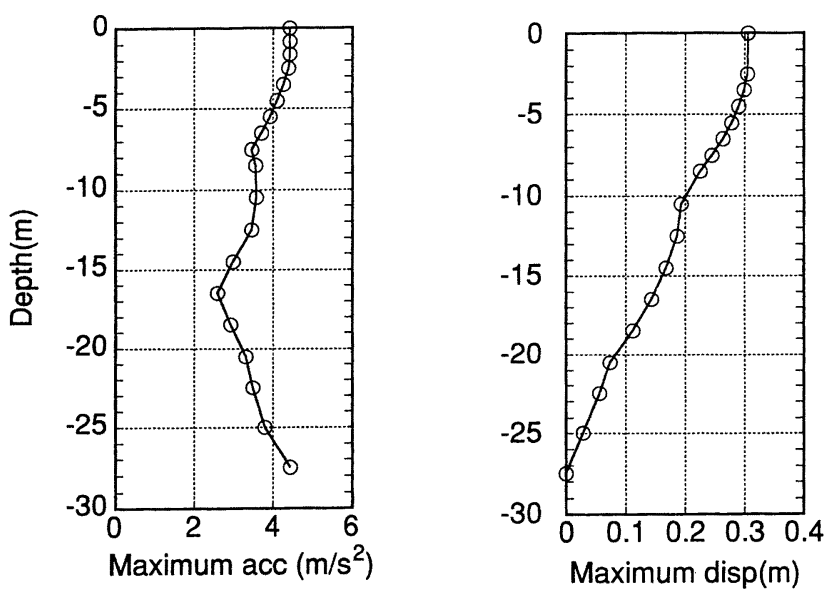

Fig. 15. Maximum response of ground 

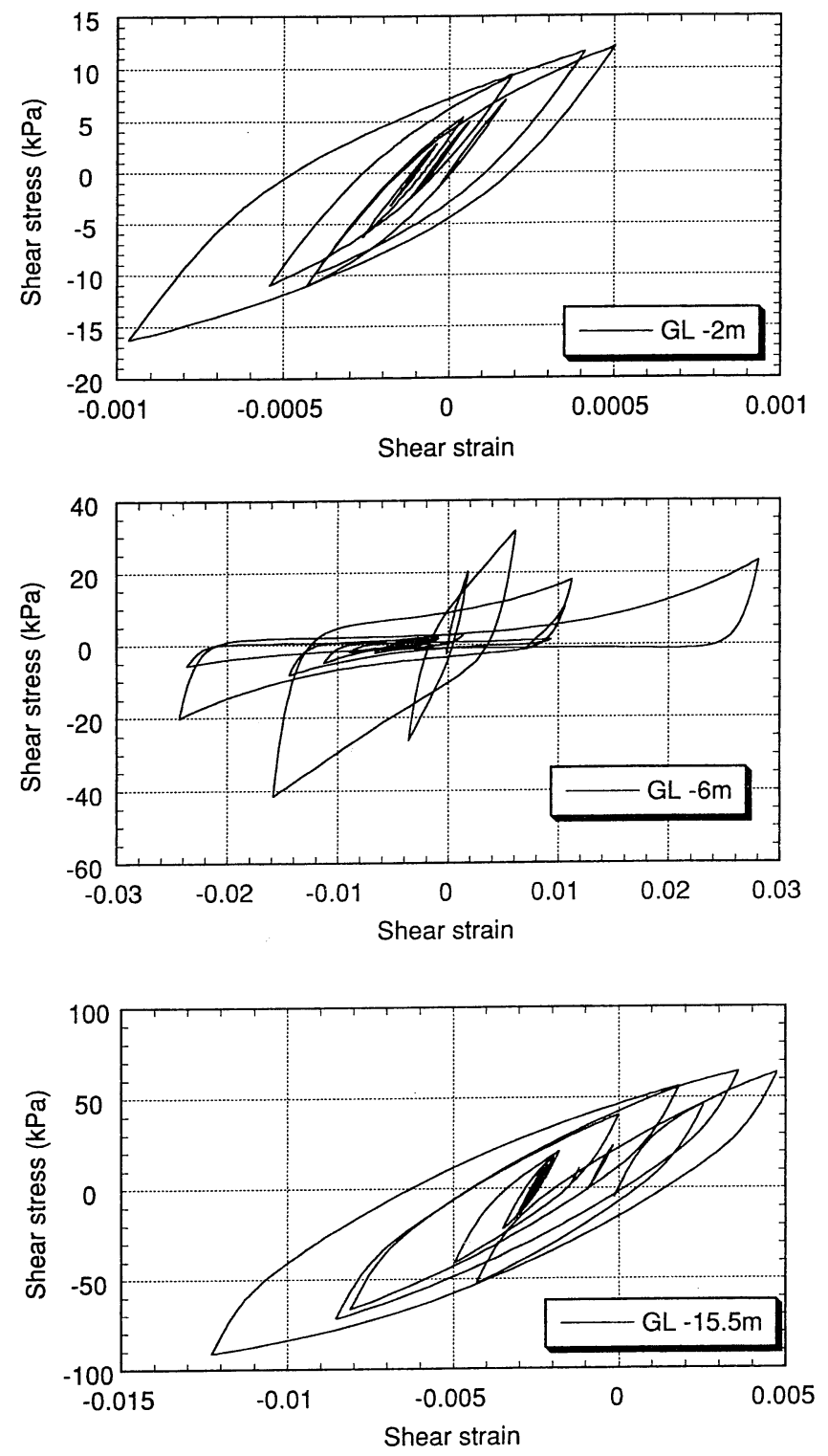

Fig. 16. Computed stress-strain relationship tios reach 1.0 at 8-9 seconds after the initiation of the shaking, suggesting that all the reclaimed fill layers below the water table liquefied around this time. The acceleration at the ground surface shows sharp peaks associated with the cyclic mobility after the initiation of liquefaction. The maximum acceleration decreases in the alluvial clay and slightly increases in the reclaimed fill layer. The maximum relative displacement of the ground surface to a depth of $27.5 \mathrm{~m}$ is about $30 \mathrm{~cm}$.

In the reclaimed fill above the water table, the maximum shear strain development is less than $0.1 \%$, so the stiffness degradation is small: about $1 / 2$ of the initial stiffness which can be determined from the shear wave velocity measurement. As a result of soil liquefaction, the reclaimed fill below the water table shows large stiffness degradation producing a maximum shear strain of $2-3 \%$. The alluvial clay layer also exhibits large stiffness degradation with a large maximum strain up to $1.5 \%$. Representative shear stress-strain relations of each layers are shown in Fig. 16. Kazama et al. (1995), Kokusho et al. (1995), and Yoshida (1995) have evaluated the strain levels developed during the 1995 Hyogoken-Nambu earthquake based on the vertical array records and analyses. The evaluated maximum strains are $1-5 \%$ for the liquefied reclaimed fill layers and $0.1-2 \%$ for the alluvial clay layzrs. The shear strains for the reclaimed fill evaluated in the current analysis lie in the middle of the range of the previous studies, while those for the alluvial clay lie in the upper range.

\section{Dynamic Response Analysis of Soil-pïle-building (SSI)} Model

A two dimensional effective stress analysis using a soilpile-building model (SSI model) was conducted. The computer program, the constitutive model and the input

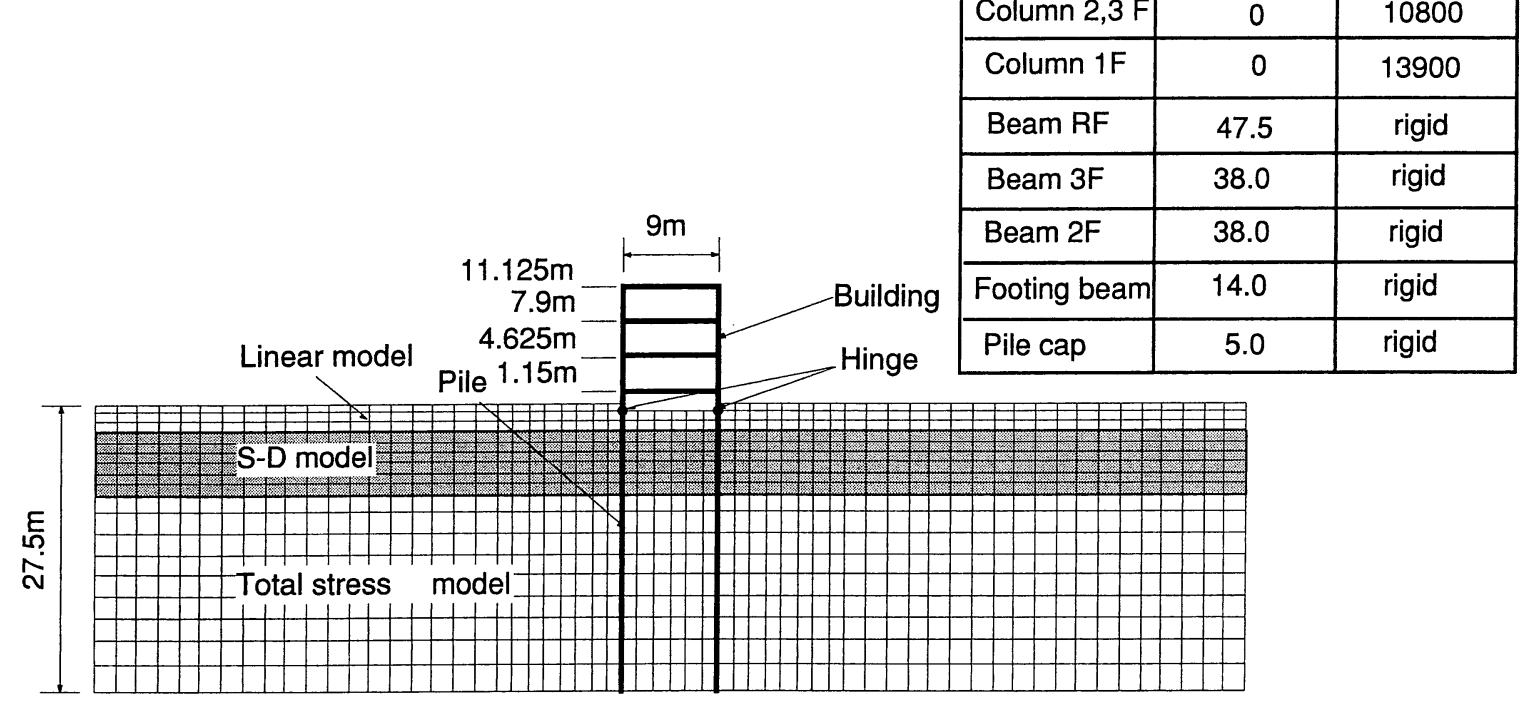

Fig. 17. Numerical model 
motion are the same as those used in the soil column analysis. The finite element mesh is shown in Fig. 17. A near surface soil deposit $27.5 \mathrm{~m}$ deep and $109 \mathrm{~m}$ wide was modeled, and was discretized into 19 layers. The base of the model was fixed, and the nodes on the side boundaries were specified to yield the same horizontal and vertical displacement.

The reclaimed fill under the water table and the alluvial clay were modeled in the same way as in the one-dimensional soil column analysis, while the reclaimed fill above the water table was modeled as linear material. To investigate the contribution of the lateral support by the unsaturated layer at the surface, the following two different values of shear stiffness for this layer were used:

(1) Secant modulus derived from the stress-strain curve in the soil column analysis as described in Fig. 16 (shear modulus is about $1 / 2$ of the initial stiffness $G_{0}=\rho V_{s}^{2}$ )

(2) Modulus of deformation $E_{0}=686 \times \mathrm{SPT}-N, \mathrm{kN} /$ $\mathrm{m}^{2}$ and the assumed Poison's ratio of 0.2 (shear modulus is about $1 / 20$ of the initial stiffness $\left.G_{0}=\rho V_{s}^{2}\right)$

The building was modeled with elastic beam elements. The properties of the beam elements are tabulated in Fig. 17. To separate the contribution of the inertial force of the building and the ground deformation on the pile stresses, a SSI model without the building model was also used. The numerical cases are listed in Table 1 .

The piles were modeled by nonlinear beam elements having hyperbolic hysteresis as shown in Fig. 18. The mo-

Table 1. Numerical cases

\begin{tabular}{c|c|c}
\hline & Stiffness of surface soil & Building \\
\hline Case D-1 & Secant modulus & With building \\
\hline Case D-2 & Modulus of deformation $E_{0}$ & With building \\
\hline Case D-3 & Modulus of deformation $E_{0}$ & No building \\
\hline
\end{tabular}

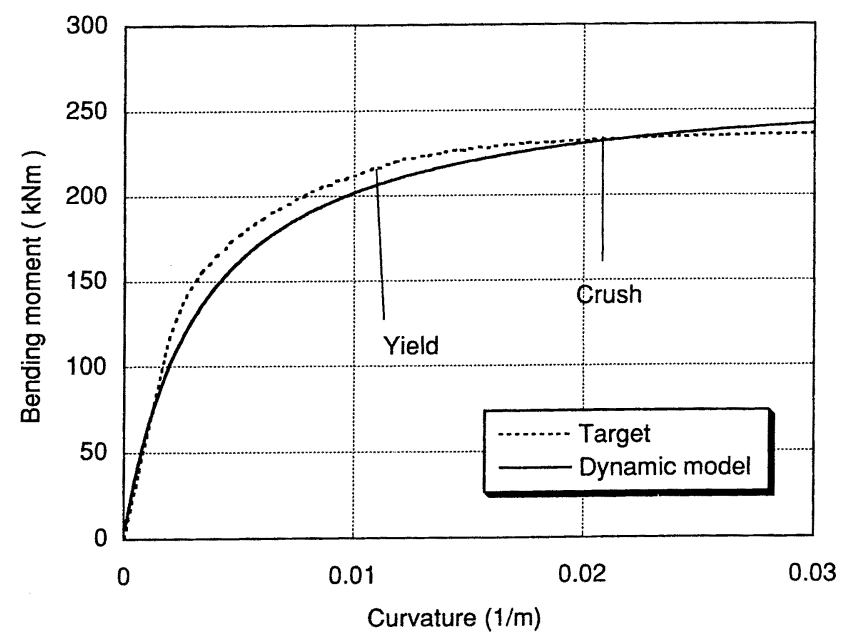

Fig. 18. Nonlinear model of pile ment-curvature relation of the pile at a dead load of 823 $\mathrm{kN}$ was first analyzed (plotted as the 'Target' in Fig. 18), and then the hyperbolic model was determined to best fit the target curve. The yield moment is $216 \mathrm{kN} \mathrm{m}$ and the crushing moment, which is defined as the compressive fiber strain development of $0.25 \%$, is $232 \mathrm{kN} \mathrm{m}$. The effect of the fluctuation of the axial load on the pile stiffness was not considered in the dynamic analyses. As there was no clear flexural failure near the pile head, and it could be assumed that no large bending moment was acting near the pile head, the pile to pile cap joint was modeled by a hinge.

The time history of the shear force acting on the pile head is plotted in Fig. 19. The shear force is considerably smaller in Case D-1 than in Case D-2, indicating the significant effect of the stiffness of the surface soil on the lateral support and thus resulting in a reduction in shear stress on the pile head. Figure 20 compares the transmission of the shear force (inertial force) of the building to the shear force of the pile at $t=6.7 \mathrm{sec}$., when the shear force at the pile head takes the maximum value. In Case D-2 where the modulus of deformation $E_{0}$ was used for the stiffness of the surface layer, about $50 \%$ of the inertial force is transmitted to the pile. The shear stress at the pile head reaches $250 \mathrm{kN}$, which corresponds to the shear

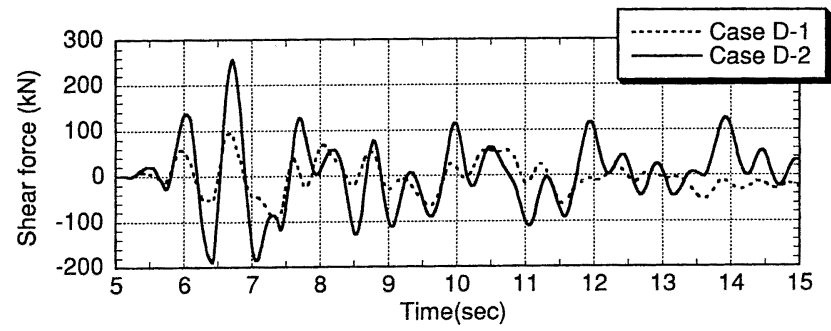

Fig. 19. Shear force at pile head

Shear force $(\mathrm{kN})$

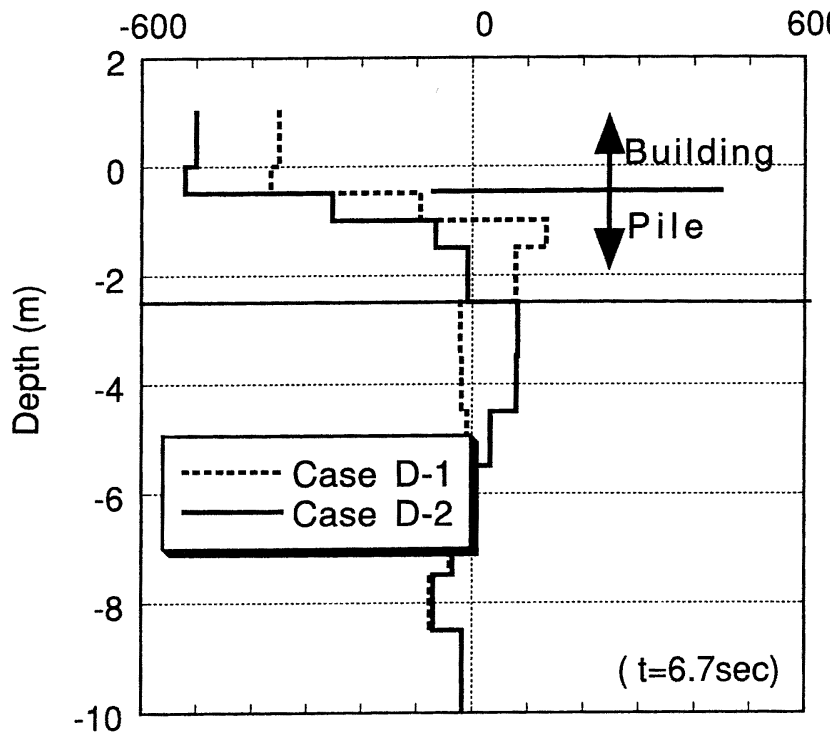

Fig. 20. Transmission of inertial force 
cracking force, showing that the computed results can explain the observed damage. In Case D-1 where the secant modulus was used for the stiffness of the surface layer, a larger portion of the inertial force is transmitted to the surrounding soil, and the resulting shear force at the pile head is about $1 / 3$ of the cracking force. These results indicate that in order to evaluate the pile stress due to the inertial force of the building, lower stiffness than that usually used in the dynamic analyses should be used for the stiffness of the surface layer in the dynamic analyses using the SSI model.

The time histories of the bending moment at depths of $1 \mathrm{~m}$ and $8.5 \mathrm{~m}$, which is roughly the border between the reclaimed fill and the underlying clay, are plotted in Fig. 21 for Case D-2 and D-3. The time histories of the acceler- ation of the top of the building and the ground surface displacement for Case D-2 are plotted in Fig. 22. The bending moment at a depth of $1 \mathrm{~m}$ for Case D-2 shows similar oscillation to the acceleration of the building, showing that the stress near the pile head is governed by the inertial force of the building. The bending moment at a depth of $8.5 \mathrm{~m}$, on the other hand, changes in the same phase to the ground surface displacement, and the existence of the building does not make significant differences. This suggests that the displacement of the ground is the major cause of stress at the middle depth.

Bending moments at times A', B', C', and D' are plotted in Fig. 23. These times are basically the same times as for the static analyses which are denoted as A, B, C, and $D$ in Fig. 14, but are slightly different (less than $0.1 \mathrm{sec}$.),
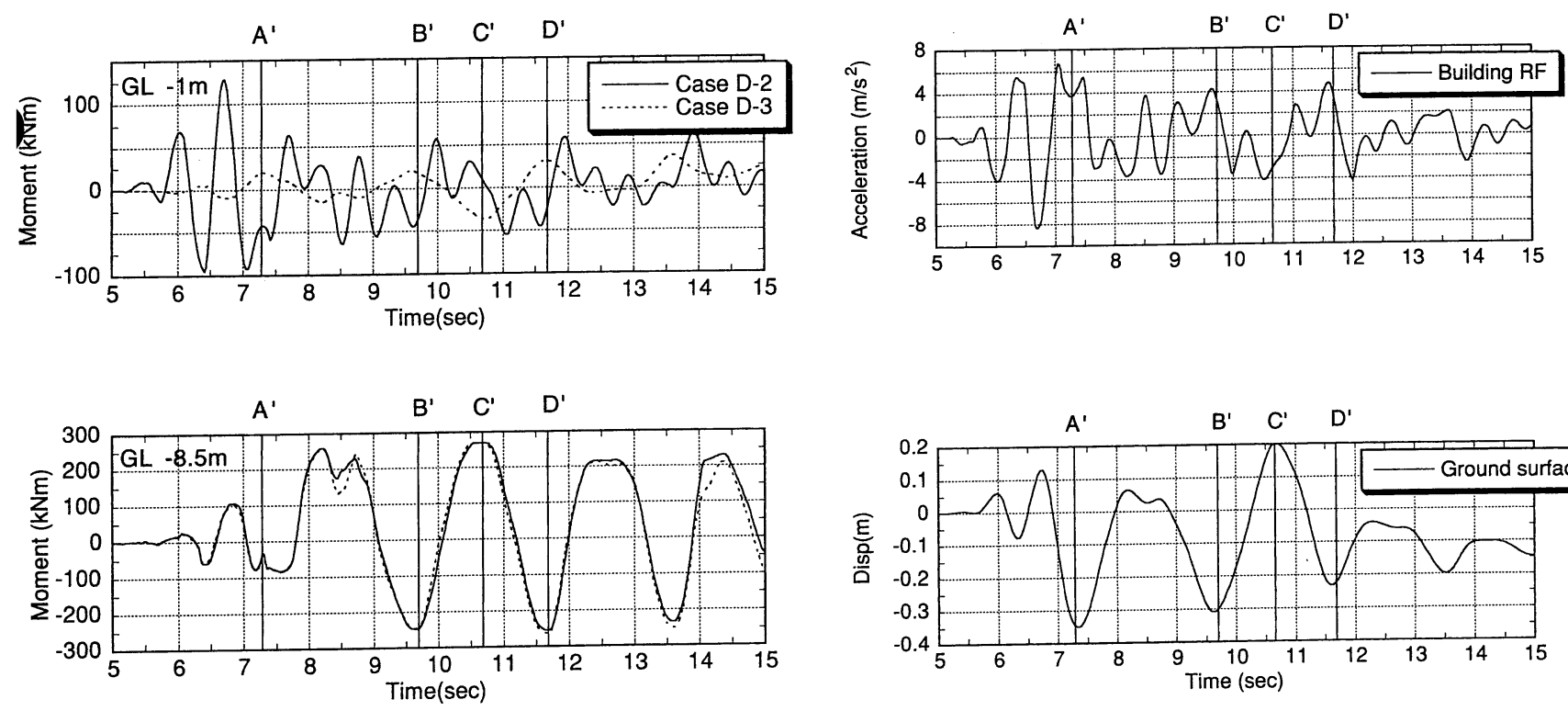

Fig. 21. Bending moment of pile

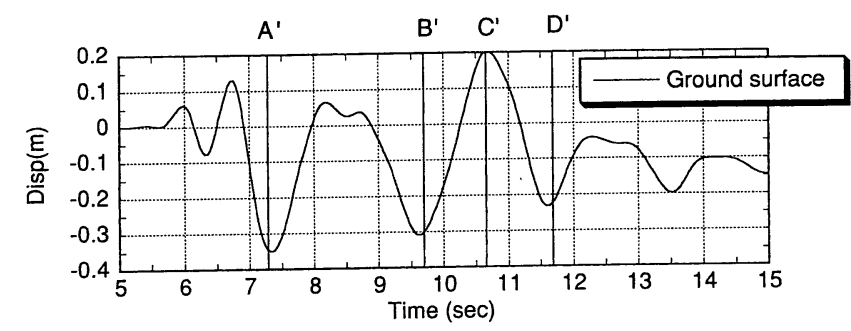

Fig. 22. Response of building and ground
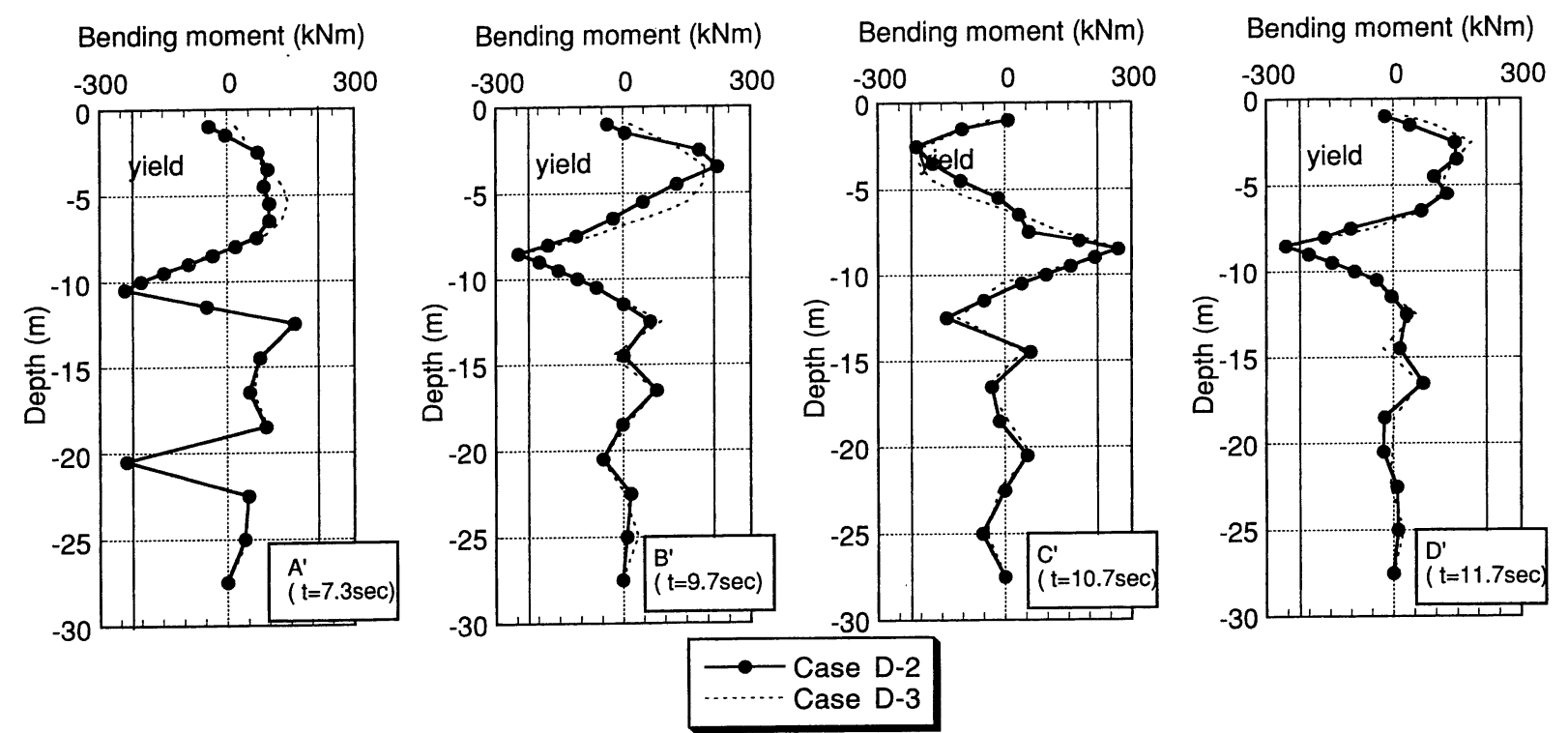

Fig. 23. Bending moment distribution 
because the times of the peak stress in the SSI model are slightly different from the times of the peak response in the soil column analysis. Comparison of Case D-2 and D-3 indicates that the effect of the inertial force on the bending moment is limited to the pile head part and the bending moment of the other part of the pile is governed by ground displacement. The bending moment at depths of $8.5-10 \mathrm{~m}$, which is considered to be the interface between the liquefied gravelly sand layer and the non-liquefied clay layer, repeatedly exceeds the yielding moment in the process of soil liquefaction.

Based on these analyses the failure process of the pile can be assumed in the following way:

(1) Shear crack at the pile head occurred at an early stage of shaking due to the inertial force of the building.

(2) During the process of liquefaction of the reclaimed fill, the bending moment of the pile at the bottom of the fill exceeded the yielding moment repeatedly, resulting in failure and permanent displacement.

\section{STATIC ANALYSIS OF PILE}

The pile stresses were computed using a model of a single pile supported by nonlinear Winkler type springs, and the applicability of this simplified method was investigated by comparing its results with the observed damage and with the results of the dynamic response analyses.

\section{Ground displacement ( $m$ )}

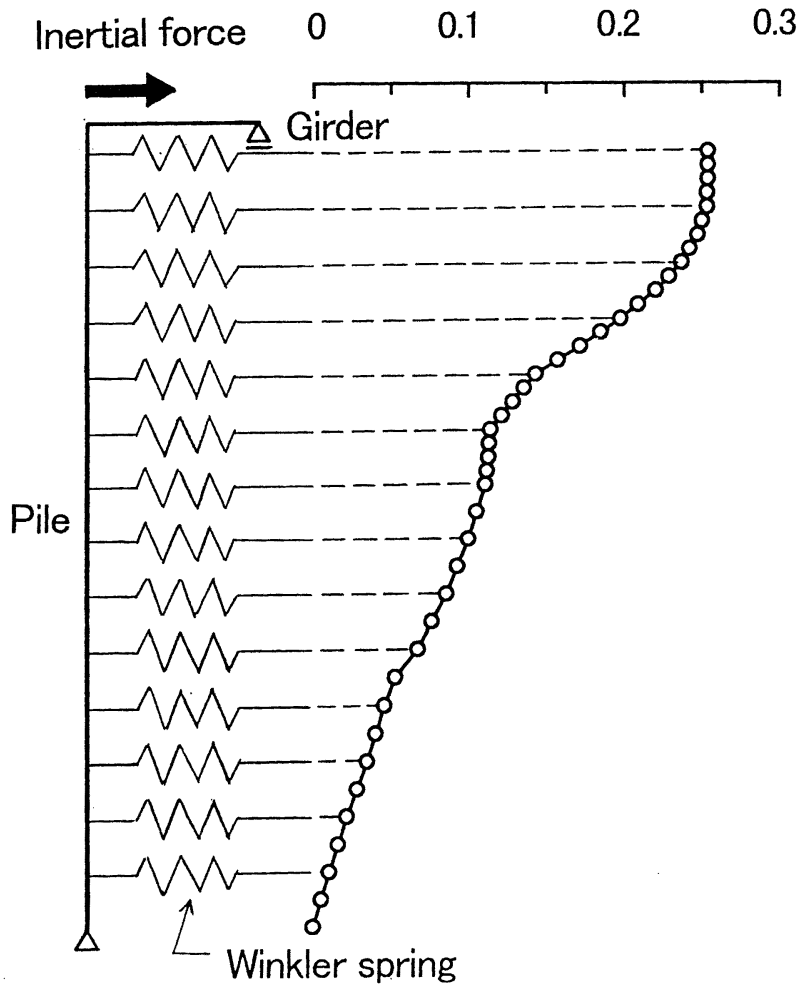

Fig. 24. Numerical model of single pile supported by Winkler-type springs

\section{Numerical Model and Applied Loads}

The numerical model, as described in Fig. 24, is composed of a nonlinear beam representing the pile, a linear beam representing the footing girder, and Winkler type springs representing subgrade reaction. The inertial force was applied to the top of the pile and the support of the Winkler springs was moved by the ground displacements, which were computed by dynamic response analysis using the $1 \mathrm{D}$ soil column model.

To determine the inertial force of the building and the axial load of the piles during the earthquake, which was necessary to model the nonlinear stiffness of the piles, a dynamic analysis of the building was conducted. The numerical model is presented in Fig. 25, which represents the east-west cross section of the building. The columns and beams were modeled by elastic beam elements and the bottom of the columns was allowed free rotation. The fundamental period of vibration was $0.37 \mathrm{sec}$. and the damping was assumed to be $2 \%$ for the fundamental period and to increase proportionally with frequency. The input motion was the computed acceleration in the dynamic analysis of ground at a depth of $0.5 \mathrm{~m}$, which corresponds to the bottom of the pile cap. The computed time histories of the inertial lateral force for a pile is shown in Fig. 26. The maximum inertial lateral force of $396 \mathrm{kN}$, which is 0.48 of the gravity load of the building, is about $80 \%$ of the inertial lateral force computed in the dynamic response analysis using the SSI model. The fluctuation of the axial force of a pile is shown in Fig. 27. The maximum fluctuation is $729 \mathrm{kN}$, which is 0.89 of the axial force due to the gravity load.

The nonlinear moment-curvature relation of the pile

\begin{tabular}{|c|c|c|c|c|}
\hline Beam RF & $11.125 \mathrm{~m}$ & & & \\
\hline \multirow{2}{*}{$\begin{array}{r}\text { Column } 3 F \\
\text { Beam 3F }\end{array}$} & \multirow{3}{*}{$7.9 \mathrm{~m}$} & & Mass (t) & $\mathrm{El}\left(\mathrm{kNm}^{2}\right)$ \\
\hline & & Column 2,3 F & 0 & 10800 \\
\hline \multirow{3}{*}{$\begin{array}{r}\text { Column } 2 \mathrm{~F} \\
\text { Beam 2F } \\
\end{array}$} & & Column $1 \mathrm{~F}$ & 0 & 13900 \\
\hline & \multirow{2}{*}{$4.625 \mathrm{~m}$} & Beam RF & 47.5 & rigid \\
\hline & & Beam 3F & 38.0 & rigid \\
\hline \multirow{2}{*}{$\begin{array}{l}\text { Column 1F } \\
\text { Footing beam }\end{array}$} & \multirow[b]{2}{*}{$1.15 \mathrm{~m}$} & Beam 2F & 38.0 & rigid \\
\hline & & Footing beam & 14.0 & rigid \\
\hline Pile cap & \multirow[t]{2}{*}{$-0.5 \mathrm{~m}$} & \begin{tabular}{|l|} 
Pile cap \\
\end{tabular} & 5.0 & rigid \\
\hline $9.0 \mathrm{~m}$ & & & & \\
\hline
\end{tabular}

Fig. 25. Numerical model of building

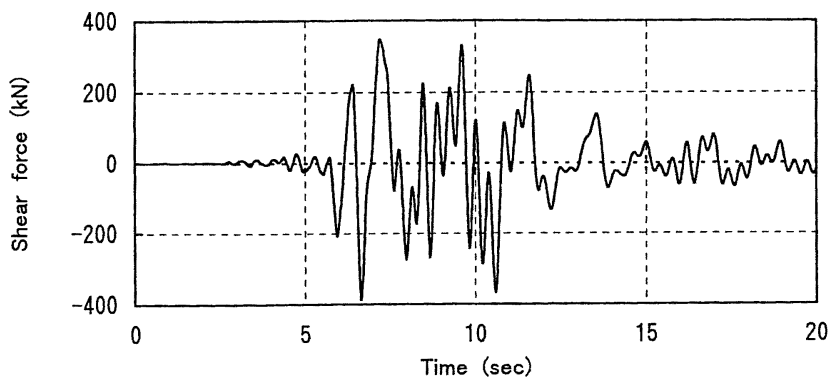

Fig. 26. Time history of shear force at pile head 


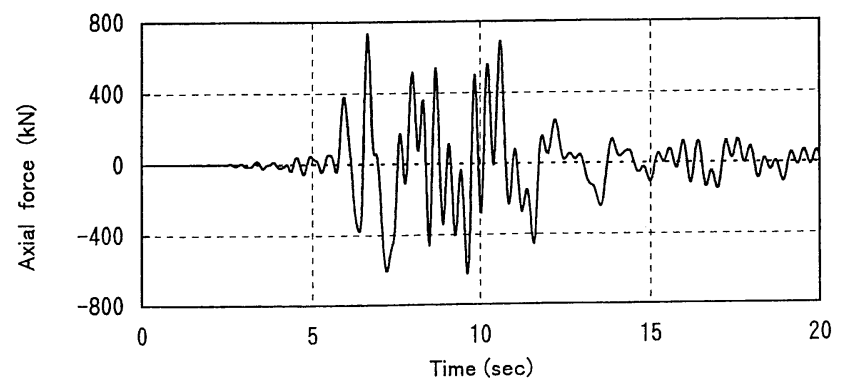

Fig. 27. Time history of fluctuation in axial force at pile head

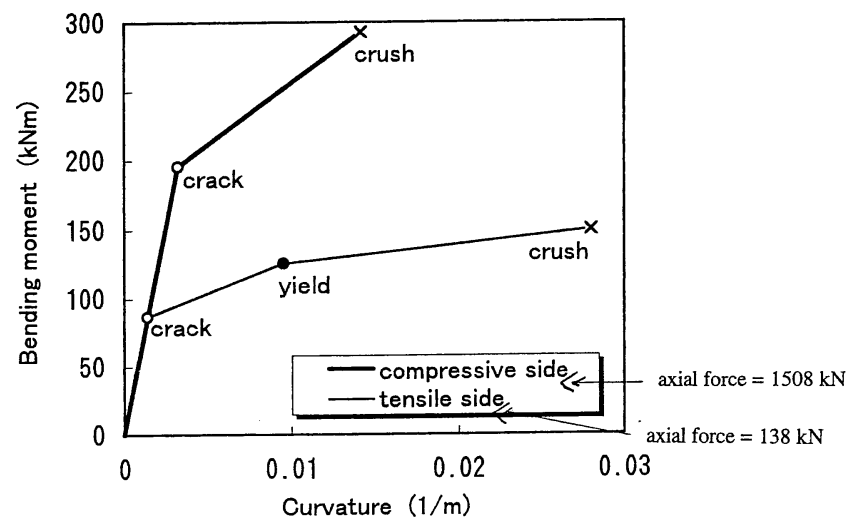

Fig. 28. Nonlinear model of pile

was modeled by tri-linear curves, in which the effect of the fluctuation of the axial force was taken into account. Figure 28 shows examples of the moment-curvature relation of the piles for the time section $C(t=10.6 \mathrm{sec})$, where the axial force is $1508 \mathrm{kN}$ for the compressive side and $138 \mathrm{kN}$ for the tensile side.

\section{Parametric Calculations}

Prior to simulation of the pile stresses during the earthquake, parametric calculations to evaluate the appropriate input parameters were conducted. The selected parameters are the reduction in the Winkler spring due to liquefaction, the degree of pile head fixity, and the reduction in the inertial force transmitted to the pile due to the subgrade reaction to footing girders. The calculations were performed at $t=9.5 \mathrm{sec}$. when a large inertial force of the building as well as large ground displacement were acting at the same time. The nonlinear property of the pile for the tensile side was used. The numerical cases are tabulated in Table 2.

The initial value of the Winkler spring $k_{h 0}$ was computed by the following equation (Japan Road Association 1997):

$$
k_{h 0}=80 E_{0} B^{-3 / 4}
$$

Where,

$k_{h 0}$ : coefficient of subgrade reaction $\left(\mathrm{kN} / \mathrm{m}^{3}\right)$

$E_{0}$ : modulus of deformation $\left(\mathrm{kN} / \mathrm{m}^{2}\right), 686 \times \mathrm{SPT}-N$ for sandy soils and $E_{50}$ of unconfined compression test for cohesive soil

\section{$B$ : $\quad$ Pile diameter $(\mathrm{cm})$}

The $E_{0}$ values used are shown in Fig. 2. In the non-liquefied layer (the reclaimed fill above the water table, the alluvial clay and the diluvial layer), the non-linearity of the spring in terms of spring deformation was considered. In the liquefied layer, the spring was linear but reduction due to liquefaction was considered.

The non-linearity of the Winkler spring in terms of spring deformation was considered in the following way:

$$
\begin{aligned}
& k_{h}=k_{h 0} ; \quad y<1.0 \\
& k_{h}=k_{h 0} y^{1 / 2} ; \quad y>1.0
\end{aligned}
$$

Where,

\section{$y$ : deformation of Winkler spring $(\mathrm{cm})$}

The reduction in the spring constants of the liquefied layer was performed in the following three ways:

(1) proportional to the computed effective stress in the dynamic analysis of ground.

(2) proportional to the square root of the computed effective stress in the dynamic analysis of ground.

(3) $5 \%$ of the initial value.

As seen in Fig. 29 the way of scaling the spring constants due to liquefaction does not result in a dramatic difference in pile stresses; a difference in the scaling factor of $0.05-0.45$ results in a difference in the pile stresses of about $30 \%$ in the reclaimed fill. The deformation of the

\begin{tabular}{|c|c|c|c|c|}
\hline \multicolumn{2}{|c|}{ External force } & \multirow{2}{*}{$\begin{array}{c}\text { Reduction } \\
\text { of soil stiffness }\end{array}$} & \multirow{2}{*}{$\begin{array}{l}\text { Degree of } \\
\text { pile head fixity }\end{array}$} & \multirow{2}{*}{$\begin{array}{l}\text { Reduction of } \\
\text { inertial force }\end{array}$} \\
\hline Ground displacement & Inertial force & & & \\
\hline Case S-1 & Case S-6 & \multirow{2}{*}{$\begin{array}{c}\text { proportional to } \\
\text { square root of }\left(1-u / p^{\prime}\right)\end{array}$} & \multirow{4}{*}{0.0 (hinge) } & considered \\
\hline- & Case S-9 & & & not considered \\
\hline Case S-2 & - & proportional to $\left(1-u / p^{\prime}\right)$ & & \multirow{4}{*}{ considered } \\
\hline Case S-3 & - & $5 \%$ & & \\
\hline Case S-4 & Case S-7 & \multirow{2}{*}{$\begin{array}{c}\text { proportional to } \\
\text { square root of }\left(1-u / p^{\prime}\right)\end{array}$} & 1.0 (fixed) & \\
\hline Case S-5 & Case S-8 & & 0.5 (half-fixed) & \\
\hline
\end{tabular}
Winkler springs, however, shows a maximum difference

Table 2. Numerical cases 

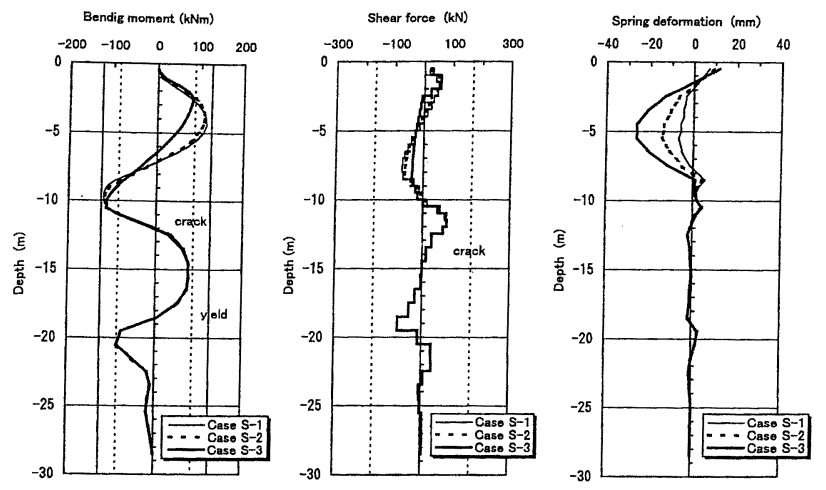

Fig. 29. Effect of reduction on subgrade reaction due to liquefaction (ground deformation)

of 5 times. In the analyses hereafter, the spring is reduced in proportion to the square root of the effective stress.

The modeling of the pile to pile cap joint is then considered. Seeing the details of the joint and judging from the observed damage, it can be assumed that the boundary is closer to a hinge than a fixed joint. Due to axial compressive force, however, the joint may carry some bending moment. So parametric calculations were conducted for three boundary conditions at the pile head:

(1) hinge: Case S-1, S-6

(2) fixed boundary: Case S-4, S-7

(3) half fixed boundary: Case S-5, S-8

As the non-linearity of the pile property is included, the definition of the 'half fixed boundary' is far from simple. In these calculations, the bending moment was first computed by an elastic pile with a fixed pile head condition, and then a half of the computed moment at the pile bead was applied as an external force to the hinge model. The computed bending moment, shear force, and spring deformation, are plotted in Figs. 30 and 31. The pile head fixity affects the stresses of the pile and the spring deformation in the 2-3 $\mathrm{m}$ zone from the pile head (about 5 times the pile diameter). The maximum bending moment due to the inertial force for the hinge condition is as large as 1.7 times that for the fixed boundary condition. The stresses of the pile due to ground displacement show little difference between fixed boundary and half fixed boundary conditions.
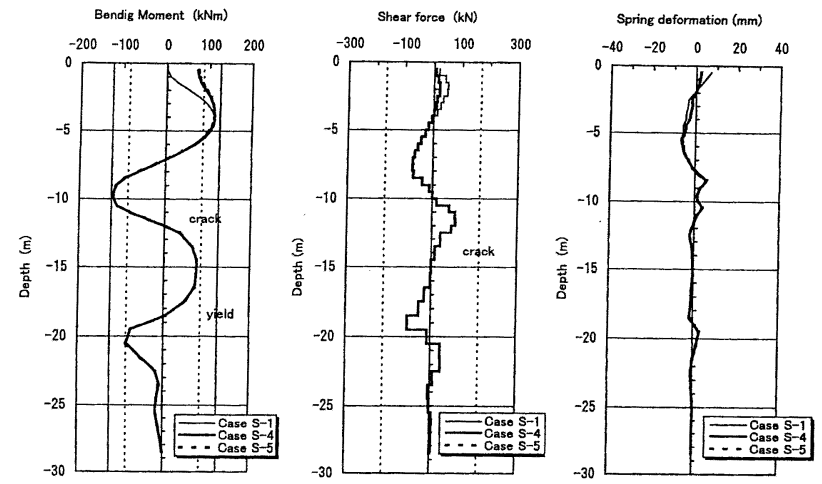

Fig. 30. Effect of pile head fixity (ground deformation)
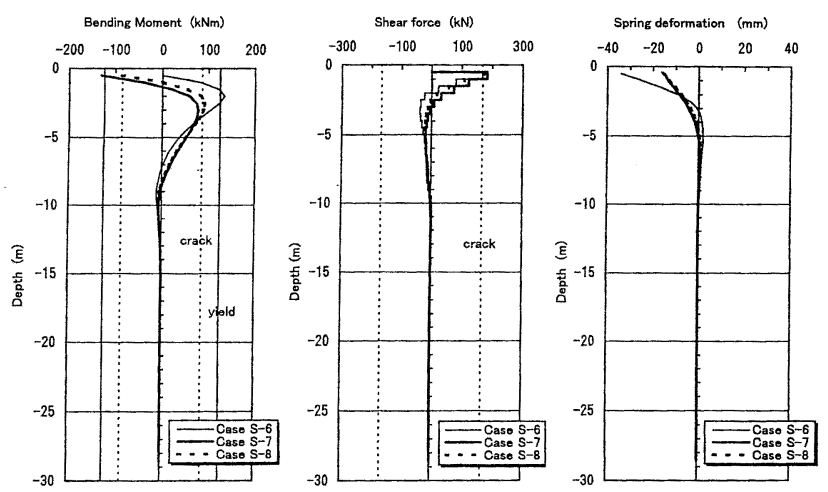

Fig. 31. Effect of pile head fixity (inertial force)
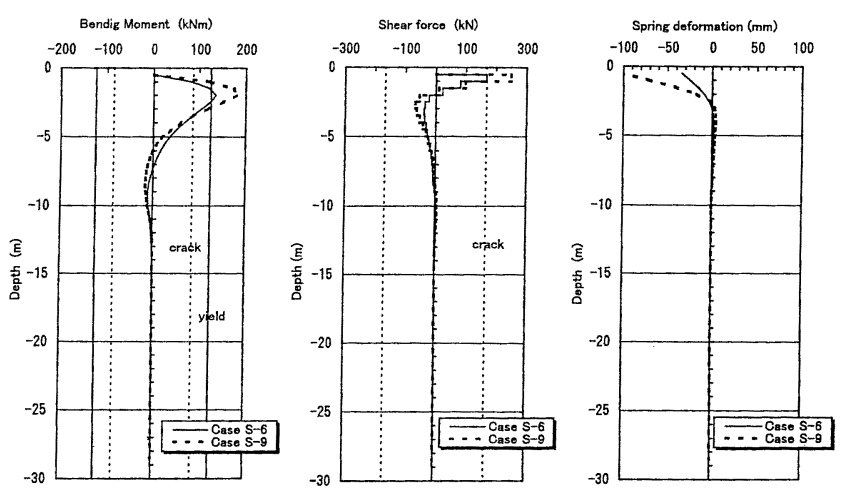

Fig. 32. Effect of subgrade reaction to footing girders (inertial force)

Table 3. Conditions for calculation

\begin{tabular}{|c|c|c|c|c|c|c|c|}
\hline \multirow{2}{*}{$\begin{array}{l}\text { Time } \\
\text { section }\end{array}$} & \multirow{2}{*}{ State } & \multirow{2}{*}{$\begin{array}{l}\text { Time } \\
(\mathrm{sec})\end{array}$} & \multicolumn{2}{|c|}{$\begin{array}{l}\text { Effective stress ratio } \\
\qquad\left(1-u / p^{\prime}\right)\end{array}$} & \multirow{2}{*}{$\begin{array}{l}\text { Ground surface } \\
\text { displacement } \\
\text { (m) }\end{array}$} & \multirow{2}{*}{$\begin{array}{l}\text { Inertial } \\
\text { force } \\
(\mathrm{kN})\end{array}$} & \multirow{2}{*}{$\begin{array}{l}\text { Fluctuation of } \\
\text { axial force } \\
(\mathrm{kN})\end{array}$} \\
\hline & & & $\begin{array}{l}\mathrm{GL}-2.5 \\
\sim-5.5 \mathrm{~m}\end{array}$ & $\begin{array}{l}\mathrm{GL}-5.5 \\
\sim-8.5 \mathrm{~m}\end{array}$ & & & \\
\hline A & Maximum ground displacement & 7.3 & 0.50 & 0.55 & -0.296 & -216 & \pm 608 \\
\hline B & Partial liquefaction & 9.5 & 0.20 & 0.10 & -0.254 & -214 & \pm 628 \\
\hline $\mathrm{C}$ & Maximum fluctuation of axial force & 10.6 & 0.20 & 0.05 & 0.169 & 224 & \pm 685 \\
\hline $\mathrm{D}$ & Complete liquefaction & 11.6 & 0.05 & 0.02 & -0.232 & -121 & \pm 458 \\
\hline
\end{tabular}


At the pile head is a rigid pile cap and a footing girder embedded into the ground to a depth of $80 \mathrm{~cm}$, and as the surrounding soil has relatively large stiffness, it can be assumed that some part of the inertial force of the building was carried by the surrounding soil. To investigate the contribution of the subgrade reaction to the footing girder, a model including an additional Winkler spring to represent the reaction of the surrounding soil of the embedded footing girder was used. The surrounding soil reached the passive state in the analysis. The contribution of the surrounding soil, therefore, was calculated by Rankine's passive soil pressure, $117 \mathrm{kN}$ per pile. The pile stress was computed for the reduced inertial force as well as for the full inertial force for purposes of comparison. Figure 32 compares the pile stresses and the spring deformation for these two levels of inertial forces. If the full inertial force is applied, the shear stress exceeds the cracking stress and the bending moment exceeds the crushing moment, while the resulting stresses with the reduced inertial force are marginal to shear cracking and flexural failure. Comparing with the observed damage, the reduction in the inertial force offers more reasonable results.

\section{Stress of Pile during Earthquake}

Analyses of the pile stresses were conducted at the four shaking times A, B, C, D tabulated in Table 3. As shown in Fig. 14, the ground surface acceleration and the displacement take peak values at these times, while the absolute values of these responses and the degree of liquefaction are different.

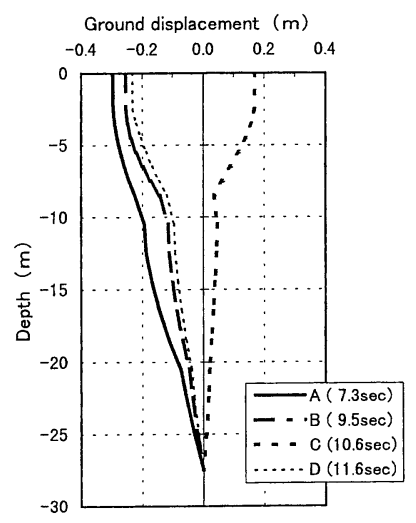

Fig. 33. Distribution of ground displacement
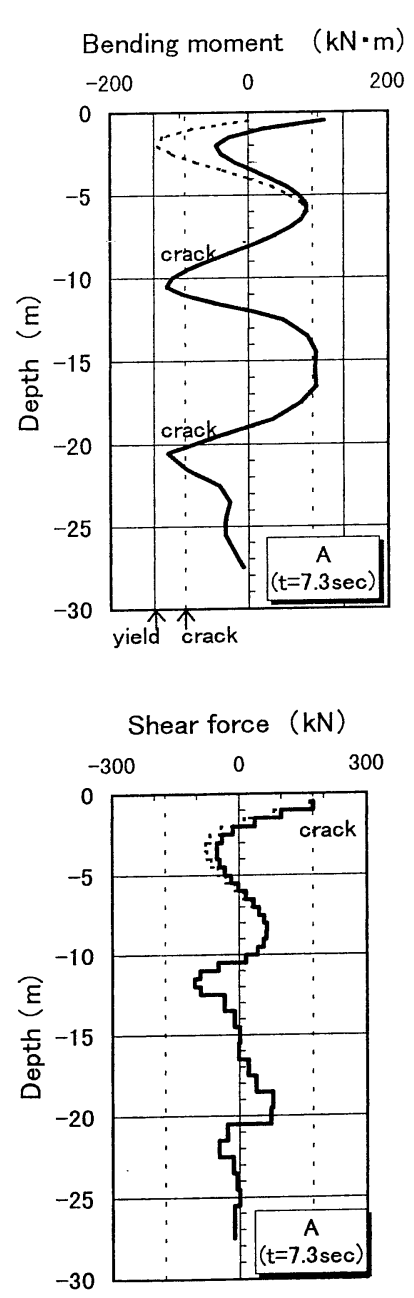

Bending moment $(\mathrm{kN} \cdot \mathrm{m}) \quad$ Bending moment $(\mathrm{kN} \cdot \mathrm{m})$ $\begin{array}{llll}-200 & 0 & 200 & -200\end{array}$
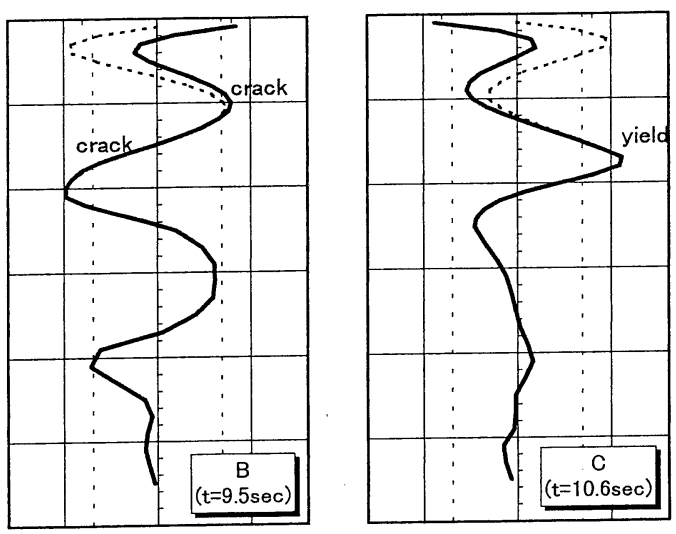

(a) Distribution of bending moment
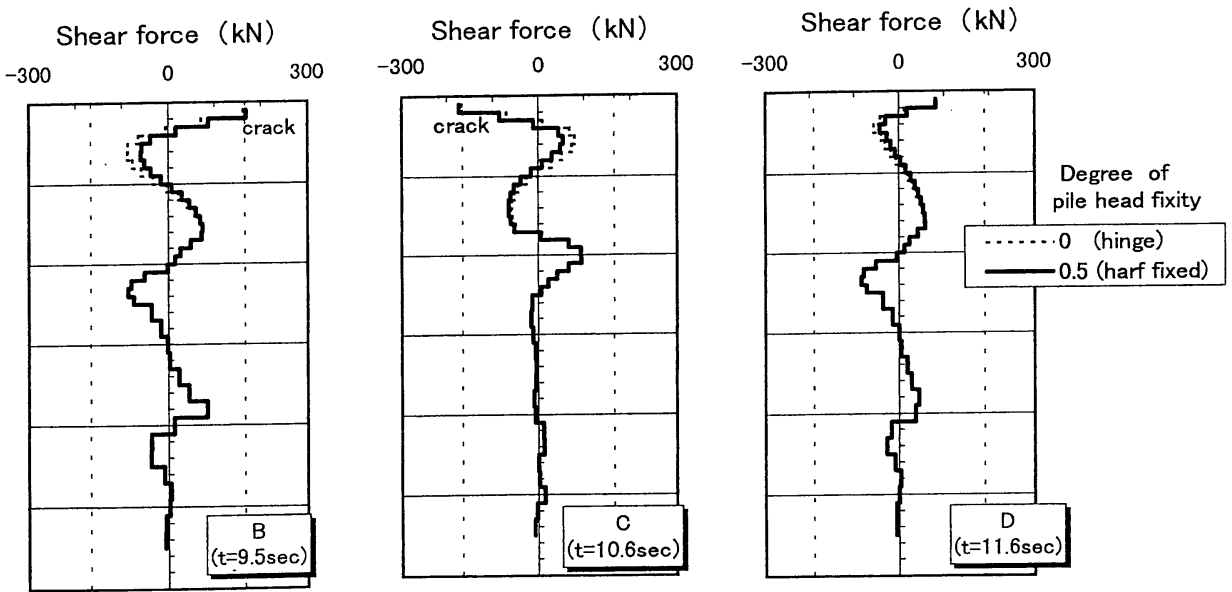

Bending moment $(\mathrm{kN} \cdot \mathrm{m})$

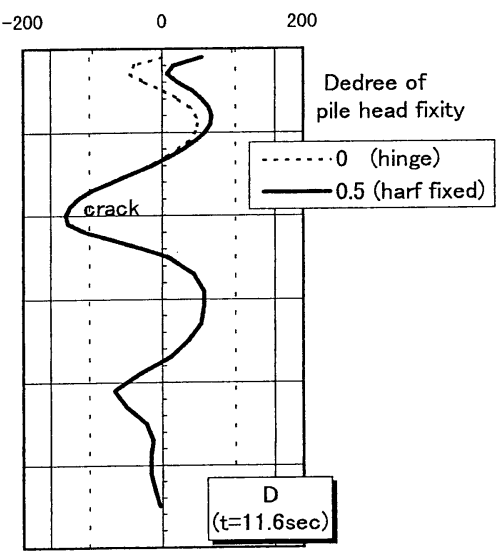

$$
\text { . }
$$

(b) Distribution of shear force

Fig. 34. Computed pile stresses for tensile side

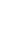



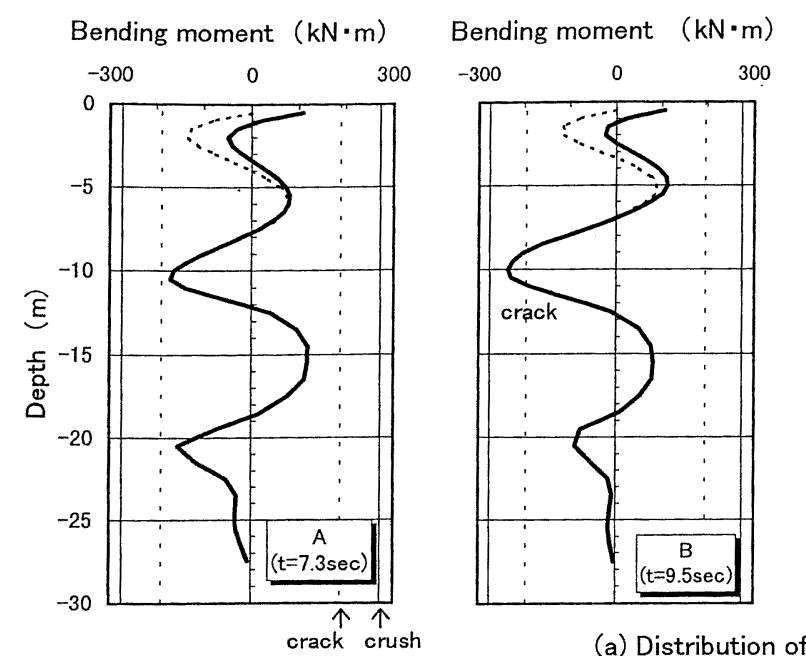

$\begin{array}{ccc}\text { Bending moment } & (\mathrm{kN} \cdot \mathrm{m}) \\ -300 & 0 & 300\end{array}$

Bending moment $\quad(\mathrm{kN} \cdot \mathrm{m})$
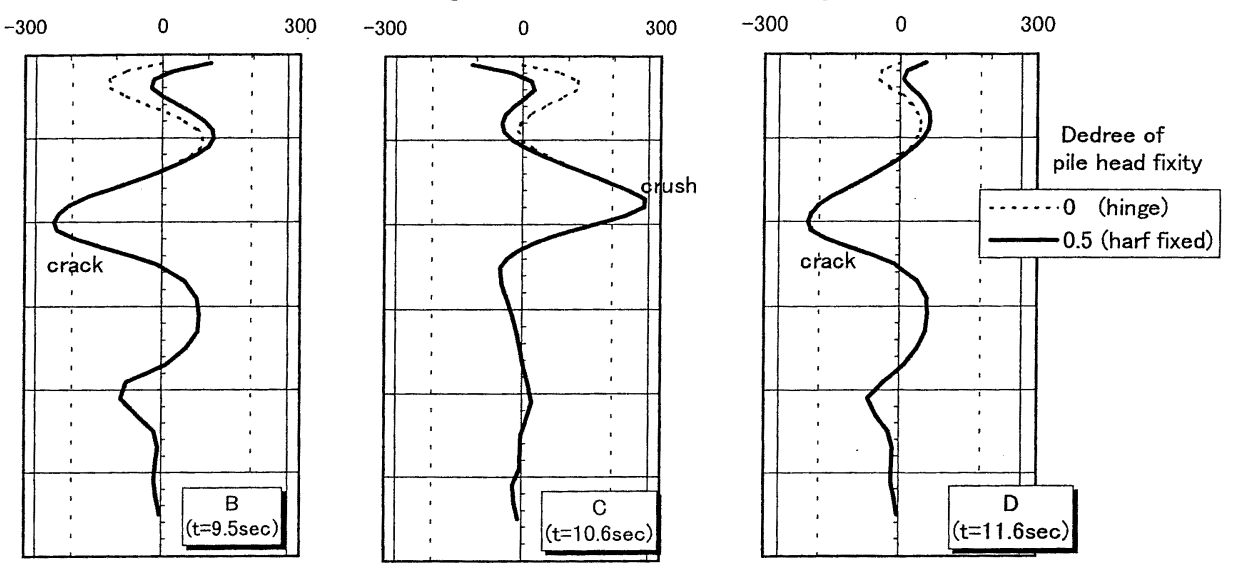

(a) Distribution of bending moment
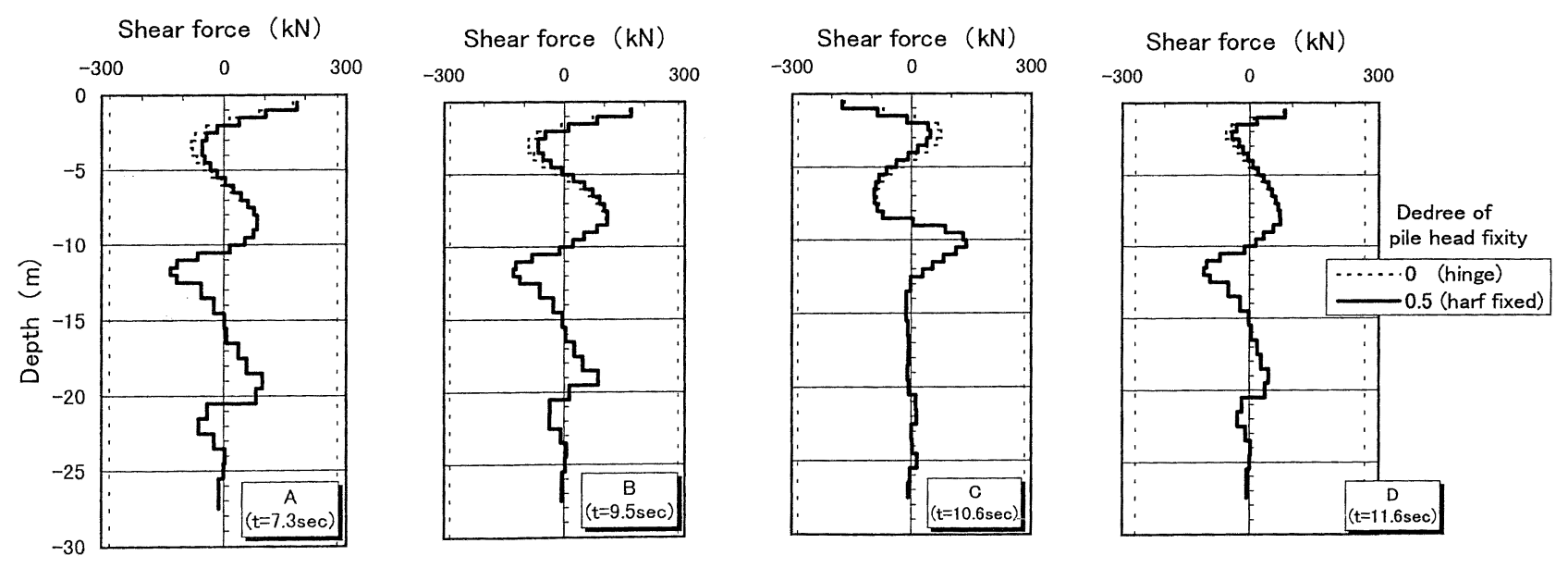

(b) Distribution of shear force

Fig. 35. Computed pile stresses for compressive side

The inertial force together with the ground displacement at each time were applied to the numerical model. The ground displacements, which are plotted in Fig. 33, are those computed in the dynamic analysis of the soil column model as shown in Fig. 12. The applied inertial forces are those computed in the dynamic analysis of the building model, after deducting $117 \mathrm{kN}$ per pile as the subgrade reaction at the embedded footing girder. The applied inertial force is $51-66 \%$ of the total inertial force of the building. The nonlinear moment-curvature relation of the pile was computed for the axial load at each time and modeled as tri-linear curves. Analyses were conducted for the piles of the tensile side and the compressive side separately. Two pile head boundary conditions, a hinge and a half fixed, were used.

Figures 34 and 35 show the bending moment and the shear force on the pile at each time, for the compressive side and the tensile side. When the pile head is modeled by a hinge, the computed bending moment around a depth of $2 \mathrm{~m}$ exceeds the cracking moment on the tensile side, while it is within the cracking moment for the half fixed condition. As there were no clear cracks observed at a depth of $2 \mathrm{~m}$, the half fixed condition for the pile head offers a more reasonable estimation of the pile stress. The bending moment distribution takes the maximum value at around a depth of $9 \mathrm{~m}$ at each times. The maximum bending moment is between the cracking and the yielding moment at times $\mathrm{A}$ and $\mathrm{B}$ and it exceeds the yielding moment on the tensile side and the crushing moment on the compressive side at time $C$. The failure of the pile is successfully predicted and the location of the failure is consistent with observations in the field. The computed shear forces at the pile head reach the cracking force at times $\mathrm{A}, \mathrm{B}$, and $\mathrm{C}$ on the tensile side. The occurrence of the shear crack at the pile head can also be explained by this pseudo-static analysis. The computed bending moment at a depth of 21 meter, which is the interface between the silty clay layer and the sand and clay layer, exceeded the cracking moment, while no cracks were observed in the investigation. The drastic difference in the stiffness of the Winkler spring could result in an excessive evaluation of the pile stress.

\section{CONCLUSIONS}

Investigation of the damage to the piles and the static 
and dynamic analyses lead to the following conclusions:

(1) The piles were damaged at the bottom of the reclaimed fill, where the occurrence of liquefaction was likely, and the piles were bent toward the southwest. The damage to the pile head was not severe. These observations indicate that a large ground displacement due to soil liquefaction was the major cause of the damage to piles.

(2) The dynamic response analyses of the soil column model suggested that liquefaction occurred at all the reclaimed fill layers causing 1 to $3 \%$ shear strains, resulting in a maximum ground surface displacement of $30 \mathrm{~cm}$.

(3) From the effective stress dynamic response analyses of the soil-pile-building model, together with the pseudostatic analyses of the pile, the failure process of the pile can be estimated in the following way:

1) Shear crack at the pile head occurred at an early stage of shaking due to the inertial force of the building.

2) During the process of liquefaction of the reclaimed fill, the bending moment of the pile at the bottom of the fill exceeded the yielding moment repeatedly, resulting in failure and the permanent displacement of the piles.

(4) In order to evaluate pile stresses due to the inertial force of the building, lower stiffness than that usually used in dynamic analyses should be used for the stiffness of the surface layer in the dynamic analyses, using the soil-pile-building model.

(5) The pseudo-static analysis of pile stresses using a model consisting of a beam on nonlinear Winkler type springs, can reproduce the observed damage reasonably well, provided that the reduction in the inertial force due to the subgrade reaction acting on footing girders is properly considered and an appropriate pile head fixity is used.

\section{ACKNOWLEDGMENTS}

This paper is a part of the joint research program by the "Committee on Building Foundation Technology against Liquefaction and Lateral Spreading" organized in the Japan Association for Building Research Promotion. The contribution and the support of the committee members for this work are appreciated. The authors thank the Public Works Research Institute, Ministry of Construction, for providing the seismic record of Higashi-Kobe Bridge Station.

\section{REFERENCES}

1) Hamada, M., et al. (1995): "The 1995 Hyogoken-Nanbu (Kobe) Earthquake liquefaction, ground displacement and soil condition in Hanshin Area," Association for Development of Earthquake Prediction.

2) Ohnishi, K., Namba, S., Sento, N., Horii, K., Tatsumi, Y. and OoOka, H. (1997): "Investigation of failure and deformation modes of piles throughout overall length at inland site in Port Island," Tsuchi-to-Kiso, Vol. 45, No. 3, pp. 24-26 (in Japanese).

3) Miwa, N., Ikeda, T., Fujii, S. and Isemoto, N. (1997): "Investigations and analysis of pile foundations damaged by soil liquefaction during the Hyogoken-Nanbu Earthquake (Part 2)," Proc., 32nd Japan National Conf. on Geotech. Engrg., pp. 921-922 (in Japanese).

4) Cubrinovski, M. (1993): "A constitutive model for sandy soils based on a stress-dependent density parameter,"' D. thesis, The University of Tokyo.

5) Kazama, M. and Yanagisawa, E. (1995): "Estimation of stress strain relation of soil during the 1995 Hyogoken-nambu earthquake by using the Port Island vertical array records," Proc. of the 23rd JSCE Earthquake Engrg. Symp. JSCE, pp. 185-187 (in Japanese).

6) Kokusho, T., Satou, K. and Matsumoto, M. (1995): "Nonlinear dynamic response of ground during the 1995 Hyogoken-nambu earthquake," Tsuchi-to-Kiso, Vol. 43, No. 3, pp. 39-43 (in Japanese).

7) Yoshida, N. (1995): "Earthquake response analysis at Port Island during 1995 Hyogoken-nambu earthquake," Tsuchi-to-Kiso, Vol. 43, No. 10, pp. 49-54 (in Japanese).

8) Japan Road Association (1997): "Specifications for road bridges," Vol. IV (in Japanese). 